\title{
Recent Advances and Challenges in Gene Delivery Mediated by Polyester-Based Nanoparticles
}

\author{
Anna Piperno (iD) \\ Maria Teresa Sciortino' \\ Elena Giusto ${ }^{2}$ \\ Monica Montesi ${ }^{2}$ \\ Silvia Panseri ${ }^{2}$ \\ Angela Scala $\mathbb{D}^{\prime}$ \\ 'Department of Chemical, Biological, \\ Pharmaceutical and Environmental \\ Sciences, University of Messina, Messina, \\ Italy; ${ }^{2}$ CNR-ISTEC, Institute of Science \\ and Technology for Ceramics, National \\ Research Council of Italy, Faenza, RA, \\ Italy
}

\begin{abstract}
Gene therapy is a promising approach for the treatment of several diseases, such as chronic or viral infections, inherited disorders, and cancer. The cellular internalization of exogenous nucleic acids (NA) requires efficient delivery vehicles to overcome their inherent pharmacokinetic drawbacks, e.g. electrostatic repulsions, enzymatic degradation, limited cellular uptake, fast clearance, etc. Nanotechnological advancements have enabled the use of polymer-based nanostructured biomaterials as safe and effective gene delivery systems, in addition to viral vector delivery methods. Among the plethora of polymeric nanoparticles (NPs), this review will provide a comprehensive and in-depth summary of the polyesterbased nanovehicles, including poly(lactic-co-glycolic acid) (PLGA) and polylactic acid (PLA) NPs, used to deliver a variety of foreign NA, e.g. short interfering RNA (siRNA), messenger RNA (mRNA), and plasmid DNA (pDNA). The article will review the versatility of polyester-based nanocarriers including their recent application in the delivery of the clustered, regularly-interspaced, short palindromic repeats/Cas (CRISPR/Cas) genome editing system for treating gene-related diseases. The remaining challenges and future trend of the targeted delivery of this revolutionary genome-editing system will be discussed. Special attention will be given to the pivotal role of nanotechnology in tackling emerging infections such as coronavirus disease 2019 (COVID-19): ground-breaking mRNA vaccines delivered by NPs are currently used worldwide to fight the pandemic, pushing the boundaries of gene therapy.
\end{abstract}

Keywords: PLGA, PLA, siRNA, CRISPR, COVID-19, CLAN

\section{Introduction}

Gene therapy refers to the use of exogenous nucleic acid molecules (NA) as drugs and tools for disease treatment at the genetic level. The goal of gene therapy is to introduce foreign genetic material into target cells for therapeutic purposes without off-target toxicity. The main approaches to gene therapy include inactivating ("knocking out") a mutated gene that is functioning improperly; replacing a mutated gene with a healthy one; and introducing foreign NA into the cells to protect them from diseases. ${ }^{1}$

The use of NA is gaining increasing interest and more than 2000 clinical trials of NA-based therapies are underway. ${ }^{2}$ The current advancements in medicine, biology and biotechnology have extended the scope of gene therapy from the "simple" transfection of plasmid DNA (pDNA) to the delivery of a variety of NA, including short interfering RNA (siRNA), microRNA (miRNA), messenger RNA (mRNA), and also the emerging CRISPR-based genome editing machinery. ${ }^{3-5}$ This challenging approach has revealed benefits in clinical trials; however, the duration of treatment
Correspondence: Angela Scala

Department of Chemical, Biological,

Pharmaceutical and Environmental

Sciences, University of Messina, Messina, Italy

Tel +390906765515

$\mathrm{Fax}+39090393897$

Email ascala@unime.it 
effects and the long-term safety (specifically when viral vectors are used as delivery systems) remain a concern to be investigated. NA suffer from some pharmacokinetic drawbacks, such as susceptibility to enzymatic degradation, limited cellular uptake, fast clearance and immunogenicity, making them less appealing for applicability compared with FDA already approved molecules. Given this, a successful gene therapy must be achieved with the assistance of highly efficient delivery systems; ${ }^{6}$ so far, the two main available ones are viral and non-viral vectors, based on the nature of the carrier involved. Recombinant virus vectors (adenoviruses, adeno-associated viruses, lentiviruses) have been the most used in gene therapy development, ${ }^{7}$ showing remarkable efficacy, as demonstrated by several commercialized products (e.g., Gendicine, Luxturna, etc). ${ }^{2}$ They rely on the highly efficient viruses' physiological cellular uptake in internalizing NA into the cells. Viral vector-based technology has been recently exploited for cancer treatment $^{7}$ and for the development of infectious disease vaccines, including against Ebola and COVID-19. ${ }^{8,9}$

During the last year, great interest and effort have been focused around the advancement of COVID-19 vaccines, ranging from conventional viral vectored vaccines to the more cutting-edge mRNA-based ones. ${ }^{9-11}$ Nowadays, the approved ground-breaking mRNA vaccines (e.g. BioNTech/Pfizer (Comirnaty) and Moderna mRNA1273), employing lipid-based nanoparticles (LNPs) as carriers for mRNA encoding SARS-CoV-2 spike glycoprotein, have demonstrated the great translational potential of nanotechnology associated with gene therapy from experimental to clinical applications.

Beside vaccines advancement, the recent progress in nanomedicine and gene therapy has also developed efficient siRNA delivery systems. One of the main examples of this success is Onpattro ${ }^{\circledR}$ (patisiran), the first commercial siRNA-based therapeutic developed by Alnylam Pharmaceuticals, approved by the FDA in 2018 for the treatment of the polyneuropathy associated with hereditary transthyretin amyloidosis. ${ }^{12}$ Onpattro ${ }^{\circledR}$ is a chemically modified anti-transthyretin (TTR) siRNA formulated in liposomes for targeted delivery to hepatocytes, the primary site of TTR synthesis, and it has marked a milestone event in the history of siRNA therapeutics development. ${ }^{13}$

The NA-based therapeutics currently commercialized, exploiting different delivery systems, pointed out that the limitations and pitfalls of viral-vector, such as the risk of inherent toxicity, pre-existing anti-vector immunity and induction of anti-vector immunity, can be solved by the development of non-viral gene delivery systems opportunely designed to balance tractability, transfection efficiency, safety and also tissue targeting. ${ }^{14}$ Compared with virus-derived vectors, non-viral vectors have several advantages: safety of administration, low immunogenic response, high gene loading, chemical design flexibility, but also almost unlimited transgene size and the possibility of repeated administration. ${ }^{15}$

Nanostructured gene delivery systems can be made of lipids, exosomes, polymers, polypeptides, graphene-family nanomaterials, inorganic materials, e.g. gold nanoparticles or their combination, although significant limitations to the use of graphene nanocarriers include their low degradability and controversial biocompatibility, as well as questions regarding their long-term safety. ${ }^{16-18}$ Herein we focus our attention on polyester-based nanovehicles for gene therapy (Figure 1), including poly(lactic-co-glycolic acid) (PLGA) and polylactic acid (PLA), which are FDA-approved and commonly employed to design drug/gene delivery systems and tissue engineering scaffolds. To date, 15 pharmaceutical products based on PLA or PLGA have been approved by the FDA. ${ }^{15}$ Polyester-based nanoparticles (NPs) have gained success in improving therapeutic efficacy of the encapsulated guest, both in vitro and in vivo, owning outstanding advantages, such as stability in the blood, high cellular uptake by endocytosis, potential for targeted delivery, controllable and sustainable release kinetics. ${ }^{19}$ Moreover, several PLGA- or PLA-based NPs have been proposed, so far, to deliver different payloads, ranging from small drug molecules, ${ }^{20-23}$ to large proteins, ${ }^{24}$ and $\mathrm{NA}^{25}$ Specifically, the application of polyester-based nanocarriers to the delivery of NA has required the incorporation of cationic components, through chemical conjugation, physical mixing, or copolymerization, resulting in a biodegradable and biocompatible delivery system with transfection efficiency comparable to commercial in vitro transfection reagents. Compared with LNPs, gold NPs and polyplexes, polyester-based nanocarriers showed lower immunogenicity and improved release profile, complete biodegradation through natural pathways without accumulation in tissues, and well-defined shapes and sizes. ${ }^{26,27}$ Furthermore, they turned out to be ideal platforms for the co-delivery of NA and chemotherapeutic drugs for cancer treatment ("combo-nanomedicine"). ${ }^{28,29}$

The newly developed genome editing technology, CRISPR (clustered, regularly-interspaced, short palindromic repeats), has shown great promise in the treatment of 


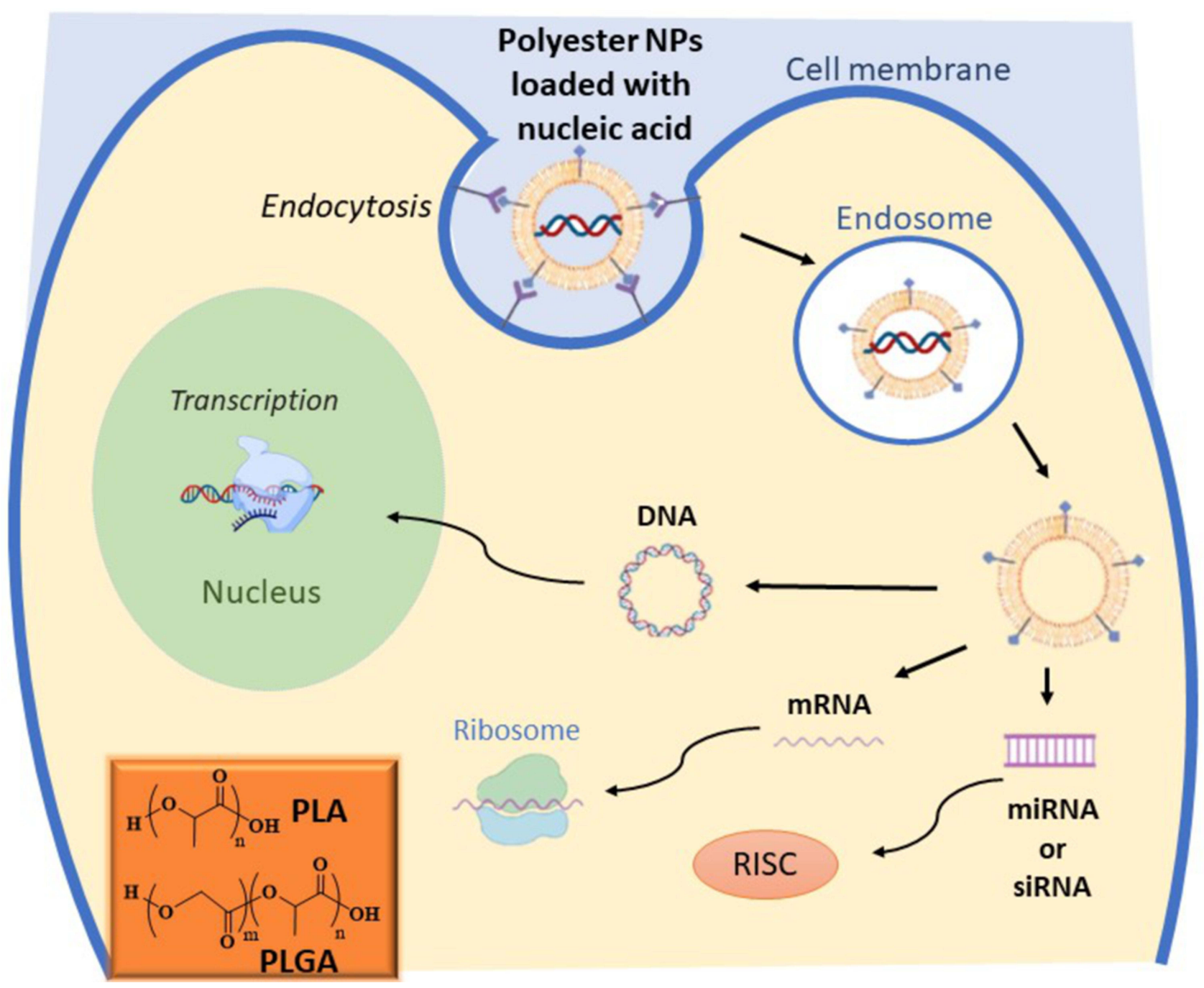

Figure I Delivery of different nucleic acids (DNA, mRNA, miRNA or siRNA) by non-viral vectors based on polyester NPs. The image represents the cell interaction and uptake, via endocytosis, of polyester-based NPs delivering NA. After endocytosis and endosomal escape, NA are released by the NPs and they follow different specific pathways. siRNA and miRNA act by binding the RNA-induced silencing complex (RISC), mRNA bind the translational machinery (ribosome) to be translated, and DNA must be transported to the nucleus to exert its activity. In the inset, the chemical structures of PLGA and PLA are reported.

several diseases $;{ }^{5}$ however, the delivery of CRISPR/Cas components to target tissues and cells requires appropriate vectors and routes of administration to ensure efficacy, safety, and specificity. Most of the common vectors successfully used in gene therapy could also be good candidates for CRISPR components delivery, but the large size of their genome editing components requires the development of alternative vectors with improved delivering capacity. In this regard, polyester-based nanocarriers have demonstrated promising ability to deliver plasmid encoding Cas9 and single guide RNA (sgRNA). ${ }^{30}$ The main strategy relies on the inclusion of CRISPR/Cas components into the core of Cationic Lipid-Assisted Nanoparticles (CLAN) composed of amphiphilic copolymers [e.g. poly(ethylene glycol)/polylactic acid (PEG-
PLA) or poly(ethylene glycol)/ poly(lactic-co-glycolic acid) (PEG-PLGA)] and cationic lipids. Recent advances in polyester-based CRISPR delivery modes will be reviewed in the following sections.

\section{Applications of Exogenous Nucleic Acids in Therapy}

Gene expression can be downregulated, increased or corrected by introducing a foreign NA to the target tissue: siRNA and miRNA can be used to trigger gene inhibition; whereas pDNA, mRNA, and CRISPR/Cas systems are usually employed to increase or correct target gene expression. Understanding the NA cellular functions is crucial to develop therapeutic candidates for the treatment of a wide range of diseases. 
siRNA are short double stranded RNA sequences (usually between 20 and $25 \mathrm{bp}$ ), found in many eukaryote species as defence mechanisms against viral mRNA exogenous infections. ${ }^{31-33}$ Once in the cytosol, the RNA Induced Silencing Complex (RISC) recognizes and incorporates the siRNA, unbounding its double strands. Within the RISC, protein Argo 2 (an RNA interfering mediated silencing protein), activated by the single strand siRNA, targets the mRNA of interest, silencing the specific region coded by the siRNA. ${ }^{34,35}$ Gene silencing induced by siRNA has been investigated in clinical trials since the early $2000 \mathrm{~s},{ }^{36}$ and globally 12 active trials are under investigation for the treatment of cancer, ocular and infectious diseases. ${ }^{37,38}$ siRNA delivery is challenging, due to their negative charge and the molecular weight $(12 \mathrm{KDa})$, making them vulnerable and degradable. In fact, the main barriers to overcome degradation before siRNAs enter the cytosol to silence their targets are mononuclear phagocytosis, kidney/glomerular filtration and lysosomal endocytosis. siRNA can be delivered both locally and systemically using modified adenovirus, adeno-associated virus, retroviruses, lentiviruses and alphaviruses, with high efficiency in transduction and expression. ${ }^{37-39}$ However the side effects associated with viral carriers (unexpected immune reactions and toxicity) have prompted the use of non-viral vectors, whose main advantages are a low immune body response and the ease in which they can be produced in large scale. Currently, the non-viral carriers for siRNA delivery ${ }^{36}$ can be listed into three main categories: lipid-based nanoparticles, polymer-based nanoparticles and conjugate delivery systems (for example N-AcetylGalactosamine, GalNAc). ${ }^{40}$ All these non-viral vectors are in clinical trials mainly for diseases such as tumors, hepatitis B and hypercholosterolemia. ${ }^{37}$ Moreover, they provide versatile platforms for the co-delivery of siRNA and chemotherapeutic drugs that may be beneficial for cancer therapy. ${ }^{29,41,42}$

Similarly to siRNA, short stranded RNA (shRNA) are processed by RISC/Argo to target the sequence of interest, but they can also be integrated into the DNA, as they consist of two complementary 19-22 bp with a short 4-6 bp loop; once transcribed, they are recognised by Dicer and spliced into the cytosol to target the right mRNA sequence. ${ }^{43}$ The delivery methods for shRNA are similar to the ones proposed for siRNA; $;^{43,44}$ moreover, also ultrasound-mediated gene delivery and nanobubbles have been investigated in vitro and in vivo for treating liver cancer. ${ }^{45}$ Recently, shRNA and long non-coding RNAs (long
ncRNAs, lncRNA) have been discovered in the regulation of many cancer pathways. LncRNA originate from different non-coding regions of genes (introns or exons around $200 \mathrm{bp}$ long) and are involved in chromatin remodelling, transcription or post-transcriptional regulation, acting in the cellular differentiation, vitality and disease. ${ }^{46}$ They have been studied for their significant role as biomarkers and as a specific therapeutic target in cancer (e.g. colorectal, breast, leukemia, bladder), being a promising tool to target oncogenes such as HOTAIR in breast cancer, and MALAT1 in metastatic lung cancer. ${ }^{47,48}$ Few studies based on RNAseq have hypothesized the important role of IncRNA in gene regulation and expression, for instance the polycomb repressive complex 2 (PRC2) has many physiological cell functions such as regulation of the $\mathrm{X}$ chromosome and chromatin structure modification, and it can be used as a therapeutic target to regulate specific tissue/organ genes to modulate their silencing or expression. ${ }^{49}$ So far, only few studies in vitro have successfully demonstrated their therapeutic applicability, but no clinical trials have been started yet. A successful IncRNA delivery has been reported by Rao et al. in treating rheumatoid arthritis (RA), using human/mouse derived exosomes as carriers for IncRNA to modulate the expression of RA characteristic genes. Moreover, it emerged that IncRNA encoding for oncogenic factors can be transported via cellular exosomes from the tumor site to the healthy neighboring cells, affecting them. A deeper understanding of these features is the starting point to develop IncRNAbased customized therapies. ${ }^{50}$

miRNA are short single stranded non-coding RNA molecules that can generate from exons or introns by the Dicer ribonuclease complex cleavage, ${ }^{51}$ differently from siRNA that directly interact with RISC. Similarly to siRNA, once in the cytosolic space, miRNA are processed in the same way by the RNAi machinery protein (RISC/ Ago2) complex, inducing the posttranscriptional gene silencing by matching at the $3^{\prime}$ untranslated region (UTR) on the target mRNA sequence via mRNA degradation or protein synthesis inhibition. ${ }^{52-54}$ Moreover, the 5' UTR has also been reported to be a less frequent target site for miRNA. ${ }^{55}$ miRNA have been investigated in preclinical and clinical studies mainly in cardiac diseases, cancer, and nervous system related diseases. For example, recent cardiac pathologies studies demonstrated that miRNA are involved in cardiac remodeling processes (hypertrophy, fibrosis and apoptosis) and they can be inhibited (blocking the overexpressed target gene) and/or replaced 
(substituting and restoring a miRNA expression modified during the disease) by ad hoc synthesized miRNA. ${ }^{53}$ The main issues related to miRNA delivery are similar to those discussed for siRNA, such as the quick degradation and difficulties crossing cell barriers. The use of viral vectors for miRNA delivery has raised concerns on their safety, especially for their toxicity and unwanted immune responses. ${ }^{56}$ Hence, the use of non-viral vectors has recently been investigated to effectively deliver miRNA. Even though kidney/liver clearance and nuclease degradation remain a major issue on the delivery system, the nonviral vectors have the advantage of being artificially modified. ${ }^{56}$ The main polymeric vectors used in recent preclinical studies are cationic polymers (such as chitosan, dextran, gelatin, easily associated to NA via their positive charge) and liposomes (liposomal NPs, biocompatible, biodegradable and chemically similar to the cell membrane). ${ }^{36,38,56}$ Preclinical trials in Phase I and II based on non-viral vectors are ongoing for several diseases such as lung, breast, pancreatic, ovarian cancers, cardiac pathologies and skin diseases. ${ }^{56,57}$

mRNA is a single strand molecule of RNA involved in the DNA-to-proteins transcription. In eukaryotic cells, RNA is transcribed from DNA, and processed by splicing (introns cleavage), capping (adding a 7-methylguanosine cap at the $5^{\prime}$ end for ribosome's recognition), editing and polyadenylation (adding a polyA tail at the 3 ', avoiding exonucleases degradation) before starting its translation into proteins by ribosomes. The main therapeutic mRNA mechanisms are based on gene and protein editing. ${ }^{58}$ The UTR regions at $5^{\prime}$ and $3^{\prime}$ are key points for their degradation, regulation and stability, ${ }^{59}$ and the sequence modification at these sites by synthetic mRNA has been proven to influence the gene translation and protein replacement in immunotherapy. ${ }^{60}$ The main advantages of using mRNA are: the high efficiency of the dose-response ratio (a small amount of mRNA can lead to highly effective immunostimulatory activity), the direct interaction with the ribosomes (instant translation) and the low toxicity and relatively high stability. ${ }^{58}$ At present, clinical trials of therapies using mRNA focus mainly on cancer and infectious diseases in the form of vaccines. The anticancer use of mRNA is based on the interaction with tumour associated antigens as promising targets for mRNA to focus on; recently, the main clinical trials found in phase I and II focus on melanoma, myeloma, glioblastoma, prostate, renal and ovarian cancer. ${ }^{60}$ mRNA has an important role in infectious diseases such as HIV, rabies, influenza and, more recently, SARS-CoV-2 ${ }^{61}$ Its employment in fighting these diseases have been successful both in preclinical and clinical trials for the high levels of induced immune response. ${ }^{60}$ Delivering mRNA within the body is challenging due to its degradation by kidneys, liver and endonucleases, instability within the cellular environment and the higher unexpected immune response. ${ }^{58,61,62}$ Recent advances in nanotechnologies have allowed the mRNA to be delivered using lipid-based and polymer-based delivery systems, optimized to elude the immune system and degradation enzymes. Lipid-based delivery systems, such as cationic lipids and the more recently discovered LNPs, base their own success on formulation with cholesterol, a zwitterionic lipid (DOPE), PEG, and ionizable lipids, all of them helping to stabilize and mimicking the body composition, eventually eluding the immune system degradation. ${ }^{58,62}$ A successful example of LNP technology are the new COVID-19 vaccines from Moderna and BioNTech/Pfizer, approved by the FDA and EMA in December 2020, that carry the viral mRNA for the translation into the envelope spike protein, successfully giving a high coverage in immune response. ${ }^{63}$ Polymer carriers play an important role in mRNA delivery as well, but their use has been found critical in aspects such as endosomal degradation, clearance and polymer dispersion and toxicity (especially for high molecular weight carriers). The most studied materials that avoid these issues are low weight polyethylenimine (PEI), poly ( $\beta$-amino) esters (PBAEs) linked with PEG to stabilize the complex within the serum, charge altering releasable transporters (CARTs) and biodegradable amino-polyesters (APEs). ${ }^{38,58,62}$

Genome therapies based on DNA have been largely studied for their great potential in the cure of cancers, cardiovascular, infectious and monogenic diseases. With the advent of new gene engineering techniques, the therapeutic synthesized DNA sequence of interest is usually coupled with a zinc-finger nucleases sequence and a transcription activator-like effector (TALE) or CRISPR/Cas9. This is a complex molecular machinery that, once entered in the cell nucleus, can act by correcting, adding or knocking down the DNA corrupted gene of interest. These steps, eventually, modify the protein expression, production and stability. ${ }^{36,64,65}$ Lentiviral and retroviral vectors have been approved as DNA carriers by the FDA and EMA for immunodeficiency, lipase-deficiency and melanoma, but, despite the high ratio of therapy success, the negative side effects (high toxicity and tumorigenic effects) on patients still raise serious concerns on their use. ${ }^{65}$ Similarly for the mRNA 
therapies, lipid- and polymeric-based therapies are the most promising due to their characteristics of stability, DNA packaging capacity and low immune response. ${ }^{64,66,67}$ Polymeric DNA vectors have the advantage of broad functionalization, amplifying their potential against body degradation. For example, the two most used polymeric vectors, poly(L-lysine) (PLL) and PEI functionalized with PEG, have been clinically investigated (phase I and II) for fibrosis and colorectal and ovarian cancers and have demonstrated to be well tolerated by the body. ${ }^{36}$ However, this kind of delivery system has to be improved as the nuclear membrane crossing and the big size of the cargo are the major barriers for their function. ${ }^{66,67}$ Amongst all, lipid-based vectors have a successful role in gene therapy thanks to their chemical composition and physical features, allowing crossing of the cell membrane, eluding endosomal uptake. The most recent lipid-based vectors on clinical trials phase I/II are DOTAP/ Chol (1,2 dioleolyl-3-N,N,N,-trimethylammonium-propane /cholesterol, targeting the tumor suppressor FUS1 in cancer), DOTMA (N-(1-(2,3-dioleoyloxy)propyl)-N,N,N-trimethylammonium, a cationic lipid targeting IL-2), GL67 (cholesterol derivate targeting cystic fibrosis) and cationic immunelipoplexes (targeting mainly p53 and RB94). ${ }^{64}$ Some of the main issues related to lipid-based vectors remain the low stability and low efficacy delivery, rapid clearance by kidneys and inflammatory responses that make them a subject still to be optimized on their design and formulation.

\section{Use of Viral Vectors as Delivery Tools: A Brief Outline}

Virus-mediated gene delivery systems exploit the virus's ability to inject their genetic material inside the host cells. Viral vectors based on DNA, RNA, and oncolytic viruses (OVs) have been used for the treatment of diseases including cancer, neurological disorders such as Alzheimer's and Parkinson's diseases, AIDS, cardiovascular disorders, rare metabolic diseases, protein replacement therapy and infectious disease vaccines. $^{7}$

Viral vectors based on both DNA or RNA viruses include herpes virus, poxvirus, adenovirus, adenoassociated virus, lentivirus, retrovirus, human foamy virus. ${ }^{68}$ Currently, several DNA gene therapeutics based on viral vectors are commercialized. As an example, Gendicine, the first-in-class gene therapy product, entered the China market in 2004 for the treatment of head and neck squamous cell carcinoma, is based on an adenovirusbased shuttling system carrying the tumor suppressor p53 gene. Clinical data indicated a good safety profile and higher response rates when combined with chemo- and radiotherapy than standard therapies alone. ${ }^{2,7}$ These positive results inspired the development of other viral vectors and, in 2017, the FDA licensed Luxturna that employed an adeno-associated viral vector serotype 2 for the delivery of a functional copy of the RPE65 gene into retinal pigment epithelial cells to compensate for the RPE65 mutation in patients with vision loss. ${ }^{69}$ So far, adenoviral vectors represent about $20 \%$ of 2500 gene therapy-associated clinical trials conducted since 1989 .

OVs administration has been proposed as a novel cancer treatment and their anticancer activity has been proved in numerous pre-clinical models and in cancer patients with localized diseases. Currently, Oncorine H101 (an oncolytic adenovirus product, approved by China for nasopharyngeal carcinoma) and Imlygic (an oncolytic herpes simplex virus-1-based drug, approved by the FDA for treating advanced melanoma) are the only two clinical approved oncolytic virus drugs. In both cases, therapeutic efficacy is related to local administration by direct injecting of OVs into the tumors. ${ }^{70}$ OVs can be tailored for specific targets by opportune engineering of their regulatory and structural components. In this regard, the virus must either replicate within the tumor and target and lyse cancer cells, inducing long-lasting tumor-specific immunity. ${ }^{1,71}$ Moreover, the safety and efficacy upon systemic administration are important properties to be pursued for a potential oncolytic virus-based drug candidate. Viral vectors might represent a significant step further for genetic dysfunction, such as cystic fibrosis ${ }^{72}$ and Duchenne muscular dystrophy, ${ }^{73}$ that are difficult targets for current gene therapy strategies. Vector immunogenicity and the consequent short duration of transgene expression are the main limitations that can be overcome by a more controlled, targeted and programmable gene delivery mediated by nanostructured biomaterials.

\section{Polyester-Based Nanoparticles for Gene Delivery}

Great efforts have been made in recent years to exploit polymeric NPs as safe alternatives to viral vectors for gene delivery. Biodegradable polyesters, including PLGA and PLA, have been highly employed to design effective gene delivery systems. ${ }^{15,25}$ The NA encapsulation in the polymeric NPs core appears to be extremely challenging due to NA dimensions and charge. The nanoformulation of these 
macromolecules can be achieved by different techniques, including nanoprecipitation, spray-drying and double emulsion (water-oil-water, W/O/W) solvent evaporation methods. Moreover, a pre-functionalization of PLGA or PLA with hydrophilic moieties and/or a pre-cationization is needed to enhance NA encapsulation efficiency and to modulate their release. ${ }^{19}$ Cationic molecules, such as PEI, polyarginine, chitosan, poly(2-dimethylamino)ethyl methacrylate (pDMAEMA), PBAEs, cationic lipids (DOTAP, DOTMA), dimethylaminoethane carbamoyl cholesterol (DC-Chol) and cationic cell-penetrating peptide (CCCP) are the most used adjuvants to improve the encapsulation efficacy of NA-loaded NPs. Furthermore, a hydrophilic polymer such as PEG or PEI grafted to PLGA or PLA NPs generally improves the in vitro and in vivo stability and the release kinetics, prolongs blood circulation times, reduces the non-specific interactions with serum proteins, opsonization and clearance by the reticuloendothelial system and, ultimately, improves transfection efficiency.

The association of PLGA with the cationic PBAEs has been recently investigated to realize a nanostructured PLGA-PEG/PBAE platform able to deliver green fluorescent protein encoding plasmid (pGFP) as a reporter gene. The NPs consisted of an outer PEG surface and a PLGA inner core containing PBAE/pGFP nanocomplexes, with the cationic PBAE improving gene payload encapsulation efficiency. A sustained gene release over a period of 8 days, with high transfection efficacy and minimal toxicity, was observed in human embryonic kidney 293 cell line (HEK 293). ${ }^{74}$

A highly efficient gene and drug delivery nanoformulation based on the combination of PLGA:PBAE (50:1) containing SOX9 siRNA-expression plasmid, retinoic acid (RA), and $\mathrm{Ag}_{2} \mathrm{~S}$ quantum dots (QDs) (PBAE-PLGA-Ag S-RA-siSOX9 or PPAR-siSOX9, Figure 2) was proposed as stem cell-based regenerative therapy for Alzheimer's disease treatment, given its ability to regenerate damaged neural networks in the brain. ${ }^{75}$ siSOX9 expressing plasmid and RA were employed for controlling neuronal differentiation of neural stem cells, whereas $\mathrm{Ag}_{2} \mathrm{~S}$ QDs were used for in vivo tracking. The NPs were prepared by an emulsion-diffusion-evaporation method; the hydrophobic RA and $\mathrm{Ag}_{2} \mathrm{~S}$ QDs were encapsulated in the hydrophobic core of PPAR; the negatively charged plasmid genes were adsorbed to the positively charged surface due to the presence of the cationic PBAE. $^{75}$
Successful gene expression in primary human astrocytes was assessed by the combination of PLGA/pDNA NPs with arginine-modified PEI polymers. ${ }^{76}$ The arginine residues enhance NPs uptake, nuclear entry of pDNA and subsequent gene expression; moreover, PEI increased chloride concentrations to induce endosomal swelling and promote endolysosomal escape; thus, it has been hypothesized that the arginine-modified PEI may enhance intracellular pDNA survival.

Different PLGA-PEI-PEG-based vectors decorated with targeting agents such as folic acid (FA) and peptides (i.e., arginylglycylaspartic acid, RGD, and isoleucinelysine-valine-alanine-valine, IKVAV) were investigated by Cao et al. ${ }^{77}$ The DNA encapsulation was carried out at different $\mathrm{N} / \mathrm{P}$ ratios (molar ratio of amine groups in PEI to phosphate groups in DNA) ranging from $1: 1$ to $16: 1$, and the transfection efficiency was assessed on HEK 293 cells and rat pheochromocytoma cell line (PC12 cells).

PLGA-PEG-PEI NPs functionalized with SP94, a peptide targeting the hepatocellular carcinoma (HCC), were loaded with an engineered triple therapeutic gene (thymidine kinase- $\mathrm{p} 53-$ nitroreductase plasmid, TK-p53 -NTR) for a gene-directed enzyme-prodrug therapy (GDEPT). ${ }^{78}$ Exogenous genes expressing metabolic enzymes introduced into target cancer cells convert nontoxic prodrugs into activated cytotoxic agents able to kill cancer cells, either by inducing DNA damage or by interfering with the cell cycle. In vivo delivery of $\mathrm{TK}-\mathrm{p} 53$ -NTR genes by SP94-targeted PLGA-PEG-PEI NPs in mice resulted in the restoration of p53-mediated apoptotic function in HCC cells, in a strong expression of suicide genes selectively in tumors, without significant off-target effects; the subsequent administration of prodrugs, ganciclovir (GCV) and CB1954, led to a decrease of tumor growth. $^{78}$

The same authors also proposed, in 2018, ultrasound (US) and microbubble (MB) mediated sonoporation for efficient delivery of the TK-NTR fusion gene into PLGA/PEI NPs to triple-negative breast cancer (TNBC) for GDEPT. US-MB image-guided delivery of TK-NTR gene led to significant expression levels of TK-NTR protein in TNBC cells and tumor reduction in vivo when animals were treated with GCV/CB1954 prodrugs. $^{79}$

The gene silencing effect of PEI-coated siRNA-PLGA hybrid micelles targeted to glypican-3 (Gpc3) on ovarian cancer cells were evaluated both in vitro and in vivo in a mouse model. ${ }^{80} \mathrm{Gpc} 3$ is a member of the heparan sulfate proteoglycans present on the cell surface as carcinoembryonic antigen, 


\section{PBAE-PLGA-Ag 2 S-RA-Plasmid (PPAR-Plasmid) Nanoformulation}

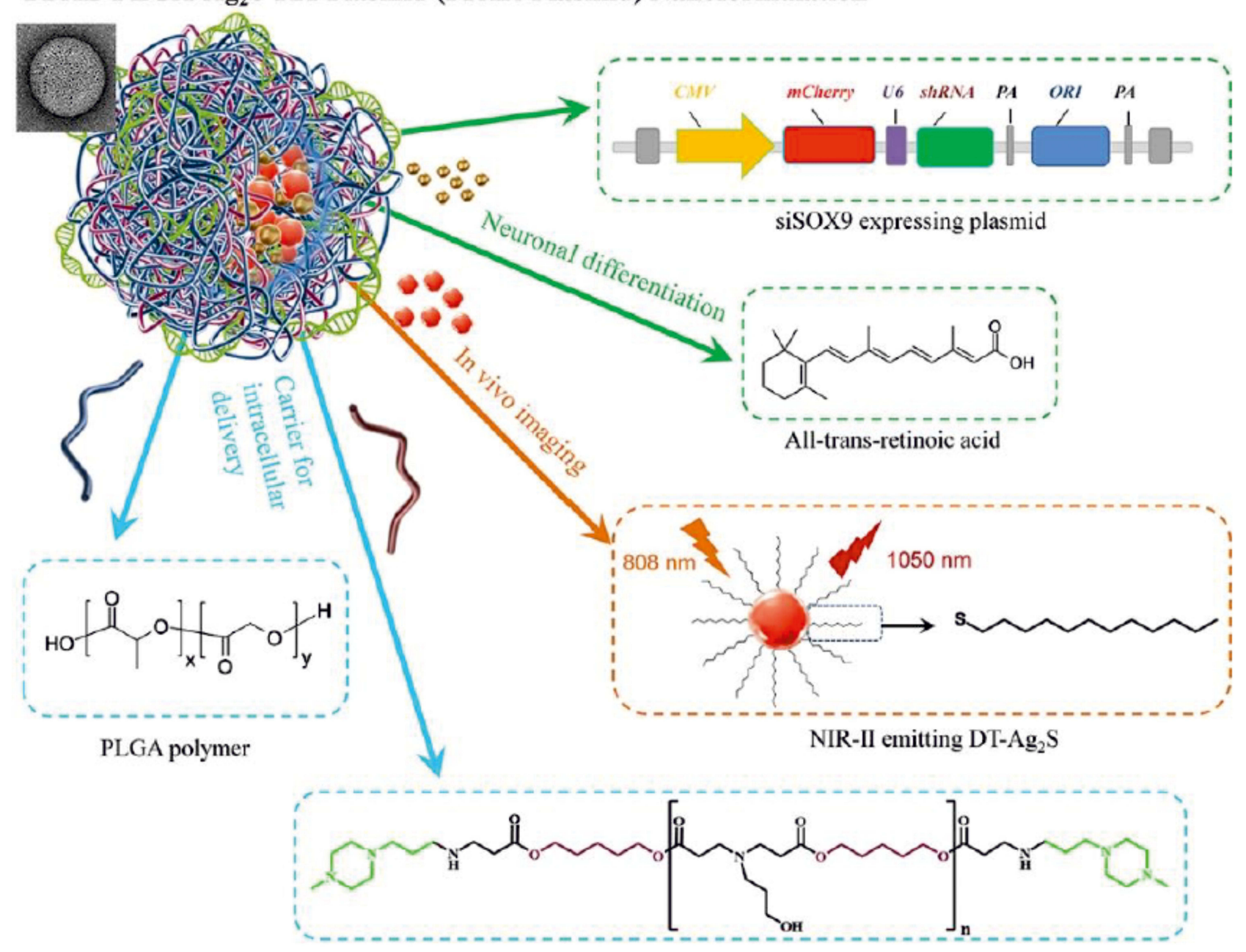

PBAE polymer

Figure 2 Schematic illustration of the structure and chemical components of multifunctional PBAE-PLGA-Ag 2 S-RA-siSOX9 (PPAR-siSOX9) nanoformulation. Notes: Reproduced with permission from Huang D, Cao Y, Yang X et al. A Nanoformulation-Mediated Multifunctional Stem Cell Therapy with Improved Beta-Amyloid Clearance and Neural Regeneration for Alzheimer's Disease. Adv Mater. 202I;33:2006357. () 202I The Authors. Published by WILEY-VCH Verlag GmbH \& Co. KGaA, Weinheim under Creative Commons Attribution 4.0 International License. ${ }^{75}$

involved in tumor progression and inflammatory reaction. The siRNA-PLGA hybrid conjugate was synthesized via a disulfide exchange and it was expected to form selfassembled micelles in aqueous solution. The nanosystem was conceived to deliver the siRNA into murine ovarian cancer cells (HM-1), promoting Gpc3 gene silencing following intraperitoneal injection in a mice model. The target Gpc3 knockdown effectively led to cancer repression in vivo. ${ }^{80}$

Vitamin B12-labeled PLGA-PEG NPs loaded with microRNAs-532-3p (miR-532-3p@PLGA-PEG-VB12 NPs) were developed as a targeting gene delivery system to be selectively delivered into transcobalamin IIoverexpressed gastric cancer cells. ${ }^{81}$ Rapidly dividing cells, such as tumor cells, have high vitamin B12 requirement and its receptor (the transcobalamin II receptor, CD320) is overexpressed in many cancer cells. The miR-532-3p@PLGA-PEG-VB12 NPs significantly decreased the expression of apoptosis repressor with caspase recruitment domain (ARC), inducing activation of the ARC/Bax/mitochondria-mediated apoptosis signaling pathway, that finally suppressed proliferation of gastric cancer cells both in vitro and in vivo. ${ }^{81}$

Hyaluronic acid- and chondroitin sulfate-modified PLGA-PEG copolymers were synthesized and employed to prepare $\mathrm{pH}$-responsive NPs loaded with DOTAP/pDNA lipoplex. ${ }^{82}$ Both types of NPs owned targeting moiety to specifically bind CD44 receptors, resulting in efficient uptake and higher transfection in CD44 high-expressed 
U87 cell lines than in CD44-negative HepG2 cells. DNA was completely released at $\mathrm{pH} 4.0$ within 24 hours, whereas a sustained release up to 72 hours was observed at $\mathrm{pH} 7.4 .^{82}$

Four cationic lipids, including DC-Chol, DOTAP, cetyltrimethylammonium bromide (CTAB), didodecyldimethylammonium bromide (DMAB) were tested for the preparation of pDNA-loaded PLGA-PEG NPs. ${ }^{83}$ The conventional $\mathrm{W} / \mathrm{O} / \mathrm{W}$ emulsion solvent evaporation method was used to prepare the NPs, loaded with an EGFP reporter gene. This model pDNA allowed a straightforward analysis of DNA transfection efficacy based on the GFP protein expression checked by confocal laser scanning microscopy (CLSM) and fluorescence-activated cell sorting (FACS). After a systematic investigation of different types of cationic lipids, pDNA concentrations, and PEGPLGA copolymers (varied PEG length and varied glycolic to lactic acid ratio), the optimized DOTAP-PEG-PLGA NPs demonstrated excellent transfection efficacy (close to half of the commercially available Lipofectamine ${ }^{\mathrm{TM}}$ 2000) and a stable and sustained expression of interleukin IL-27 pDNA in murine model. ${ }^{83}$

In 2019, Wang and coworkers proposed the use of CLAN based on PEG-PLGA copolymer to encapsulate and deliver siRNA into macrophages and $\mathrm{B}$ cells for Bruton's tyrosine kinase (BTK) gene silencing. ${ }^{84}$ BTK in macrophages and $\mathrm{B}$ cells has been demonstrated to be a promising therapeutic target for RA. CLAN siRNA was $_{\text {s. }}$ prepared by DOTAP-assisted self-assembly of the amphiphilic PEG-PLGA copolymer, through a double-emulsion solvent evaporation method. The in vitro and in vivo investigation pointed out a great reduction of joint inflammation, without toxicity. ${ }^{84}$

The versatility of CLAN has been deeply investigated by Wang and coworkers and the effectiveness of "CLAN nanomedicine" for the delivery of siRNA and CRISPR/ Cas9 plasmid in several disease models has been demonstrated by their extensive scientific production. ${ }^{30,84,85}$ Recently, the use of CLAN has been fruitfully extended also to vaccine application, as a clinically translatable mRNA delivery system for cancer immunotherapy. ${ }^{86}$ The use of mRNA encoding tumor-associated antigen has gained increasing interest in recent years and mRNAbased vaccines hold prominent advantages compared with conventional approaches, such as the avoidance of nuclear entry and the high safety without integrating into host genome. ${ }^{87}$ In this regard, Wang and coworkers demonstrated that the intravenous administration of
CLAN formulation based on PEG-PLGA and N,N-bis (2-hydroxyethyl)-N-methyl-N-(2-cholesteryloxycarbonyl aminoethyl) ammonium bromide (BHEM-Chol) encapsulating mRNA encoding ovalbumin (OVA) stimulates the maturation of dendritic cells (DCs) and provoked in mice a strong OVA-specific T-cell response and slowed tumor growth in an aggressive E.G7-OVA lymphoma model (Figure 3). ${ }^{86}$

A series of macrophage-targeted NPs has been prepared by self-assembly of a PLGA-PEG di-block copolymer and a cationic lipid-like molecule (G0-C14) which is composed of a cationic head group (able to electrostatically interact with the therapeutic NA) and a flexible hydrophobic tail (for the self-assembly with PLGA-PEG). ${ }^{88}$ NPs were engineered with different carbohydrates, including mannose, galactose, and dextran for targeted delivery of mRNA and pDNA to macrophages. The influence of carbohydrate decoration on the targeting capacity and transfection efficacy were deeply investigated, showing that dextran-functionalized NPs had the highest endocytosis at various concentrations and the best mRNA transfection efficiency. ${ }^{88}$

Recently, Ajdary et al. have demonstrated that a combinatorial delivery of antigen and Toll-like receptors (TLR) agonists via PLGA NPs modulates Leishmania major-infected-macrophages activation, which is crucial for the parasite elimination. ${ }^{89}$ PLGA NPs were loaded with soluble-antigen of Leishmania (SLA), agonists of TLR7/8 (R848) and TLR1/2 (Pam3CSK4). The effects of single-, dual-, triple-PLGA NPs and soluble SLA, R848, Pam3CSK4, and their different combinations were determined on pro-inflammatory cytokines (IL-1 $\beta$, IL-6, and TNF- $\alpha$ ) and inducible nitric oxide synthase (iNOS) genes expression by qPCR at different times, in Leishmania major-infected-macrophages. Among the different nanoformulations, the triple (SLA-R848-Pam3CSK4)-loaded NPs promoted the highest activation of macrophages, followed by dual SLA-Pam3CSK4 and by the SLA-R848 NPs. The co-encapsulation resulted in a strong immune response, with increased and prolonged expression of cytokine and iNOS, and leishmanicidal activity, suggesting a longer availability or sustained delivery of the NPs into the macrophages. These findings highlighted the advantages of co-encapsulation of antigen and TLR agonists as adjuvants to induce immune responses against $L$. major infection for potential vaccine development. ${ }^{89}$

A smart biomimetic gene delivery system based on amphiphilic PLGA-PEI NPs with typical core-shell structure, loaded with pZNF580 plasmid, and coated with 


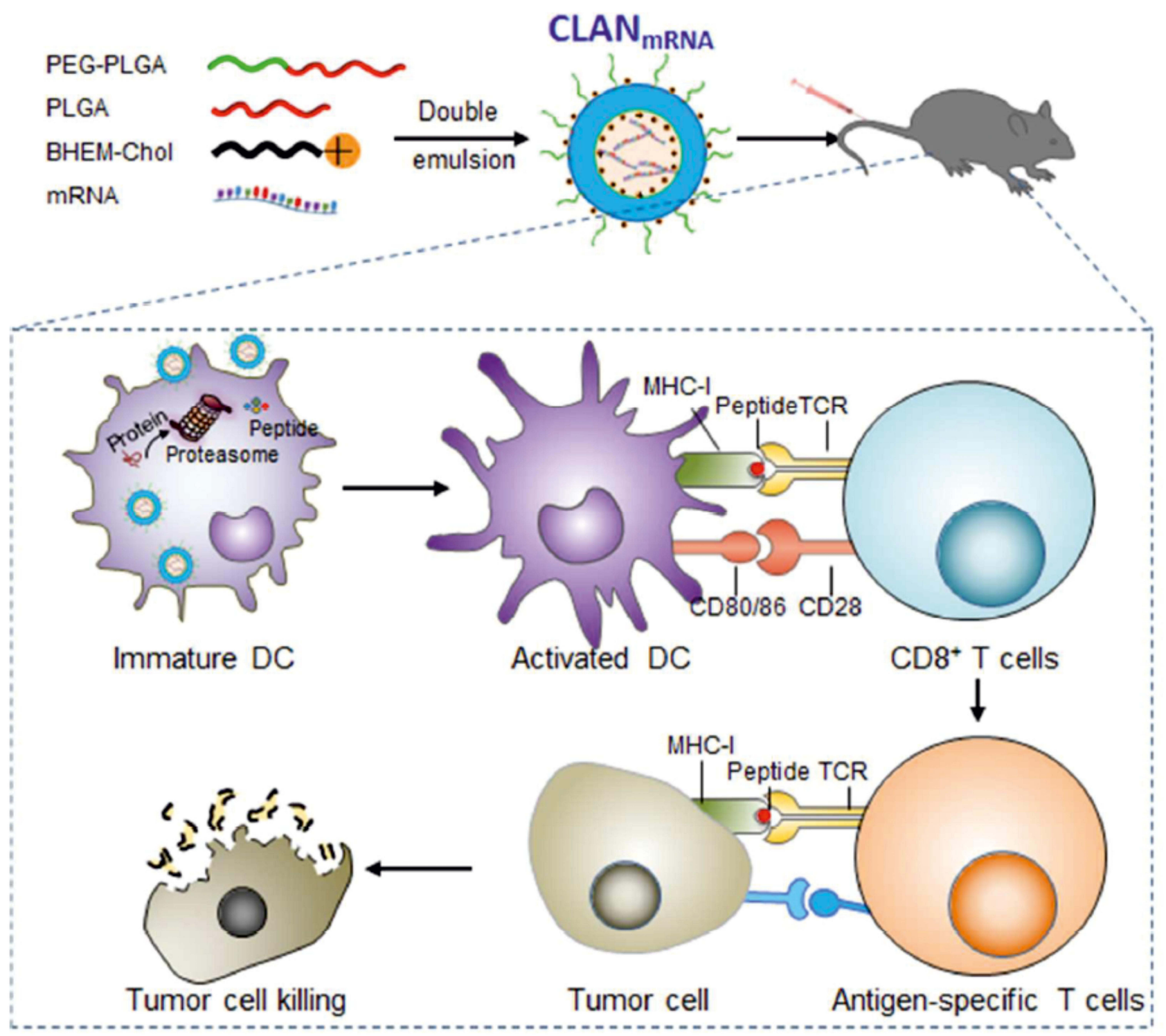

Figure 3 Schematic illustration of CLAN encapsulating mRNA coding for the model immunology protein OVA that stimulates the maturation of DCs, promotes the activation and proliferation of antigen-specific $\mathrm{T}$ cells and induces a robust anti-tumor immune response in an aggressive E.G7-OVA lymphoma murine model.

Notes: Reprinted with permission from Fan YN, Li M, Luo YL, et al. Cationic lipid-assisted nanoparticles for delivery of mRNA cancer vaccine. Biomater Sci. 2018;6:3009$3018,{ }^{86}$ permission conveyed through Copyright Clearance Center, Inc.

nano-sized red blood cell (RBC) membrane by electrostatic interaction, was proposed to obtain high blood compatibility and long circulation time. The natural cell membrane coating of NP/pZNF580/RBC assured immuneescaping ability and high transfection efficiency. ${ }^{90}$

A polydopamine-modified suture carrying PLGA-PEI nanoparticle/pEGFP-basic fibroblast growth factor (bFGF) and pEGFP-vascular endothelial growth factor A (VEGFA) complexes was developed with the aim to transfer the growth factor genes into injured tendon tissues to promote healing. ${ }^{91,92}$ After tendon tissues were sutured, the nanoparticle/plasmid complexes could diffuse from sutures to tendons transfecting genes, increasing the expression of growth factors useful for the treatment of the injury. In vitro release experiments demonstrated that plasmids are continuously released for 28 days. The nanoparticle/plasmid complex-coated sutures significantly improve flexor tendon healing strength compared with the corresponding unmodified sutures, especially at 4-6 weeks after operation. ${ }^{91,92}$

The plasmids expressing VEGF-A and the platelet derived growth factor (PDGF-B), two factors that accelerate regenerative processes by promoting neovascularization, granulation tissue formation, synthesis of collagen and re-epithelialization, were loaded into PLGA-PEI 
nanospheres to upregulate genes expression in diabetic rats with the aim to improve wound healing in the case of diabetic foot ulceration (DFU). ${ }^{93}$

Magnetic NPs prepared by double-emulsion solvent evaporation method from PEI-coated $\mathrm{Fe}_{3} \mathrm{O}_{4}$ NPs, PEIPLA-PEG-folate and plasmid DNA (pEGFP-N1) were decorated with the EPPT peptide (Glu-Pro-Pro-Thr) for targeting MUC-1 receptors overexpressed on breast cancer cells MCF-7. The NPs demonstrated good stability under physiological conditions and released encapsulated plasmid DNA rapidly under acidic conditions. The endosomal escape capability of the incorporated DNA to the cytoplasm before fusion with lysosome avoided gene degradation from lysosomal enzymes including DNase. ${ }^{94}$

A folate-decorated gene delivery system (FA-DMA) consisting of DOTAP, PEG-PLA, and FA-PEG-PLA was recently proposed as carrier for CCL19 plasmid for targeted cancer immunotherapy (Figure 4). ${ }^{95}$ CCL19 emerged as a candidate immunomodulator for colon cancer therapy by increasing the possibility of interaction among dendritic cells, T and B cells in secondary lymphatic tissue, thus regulating the primary (or secondary) adaptive immune responses. The folate decoration improved the transfection efficiency of CCL19 in CT26 cells and the treatment of tumor-bearing mice with FA-DMA/CCL19 remarkably inhibited tumor growth and reduced the burden of ascite formation. ${ }^{95}$

The same authors proposed a similar nanosystem (DMA) without folate decoration as a carrier for interleukin-15 (IL15), a potent pro-inflammatory cytokine, which has emerged as a candidate immunomodulator for the treatment of colorectal cancer, ${ }^{96}$ and for interleukin-12 (IL12), an ideal candidate for tumor immunotherapy. ${ }^{97}$ The growth of CT26 cells transfected with DMA-pIL15 or DMA-pIL12 was inhibited in vitro by cell apoptosis; moreover, the treatment of tumor-bearing mice with both nanoformulations significantly inhibited tumor growth in vivo by inhibiting angiogenesis, promoting apoptosis,

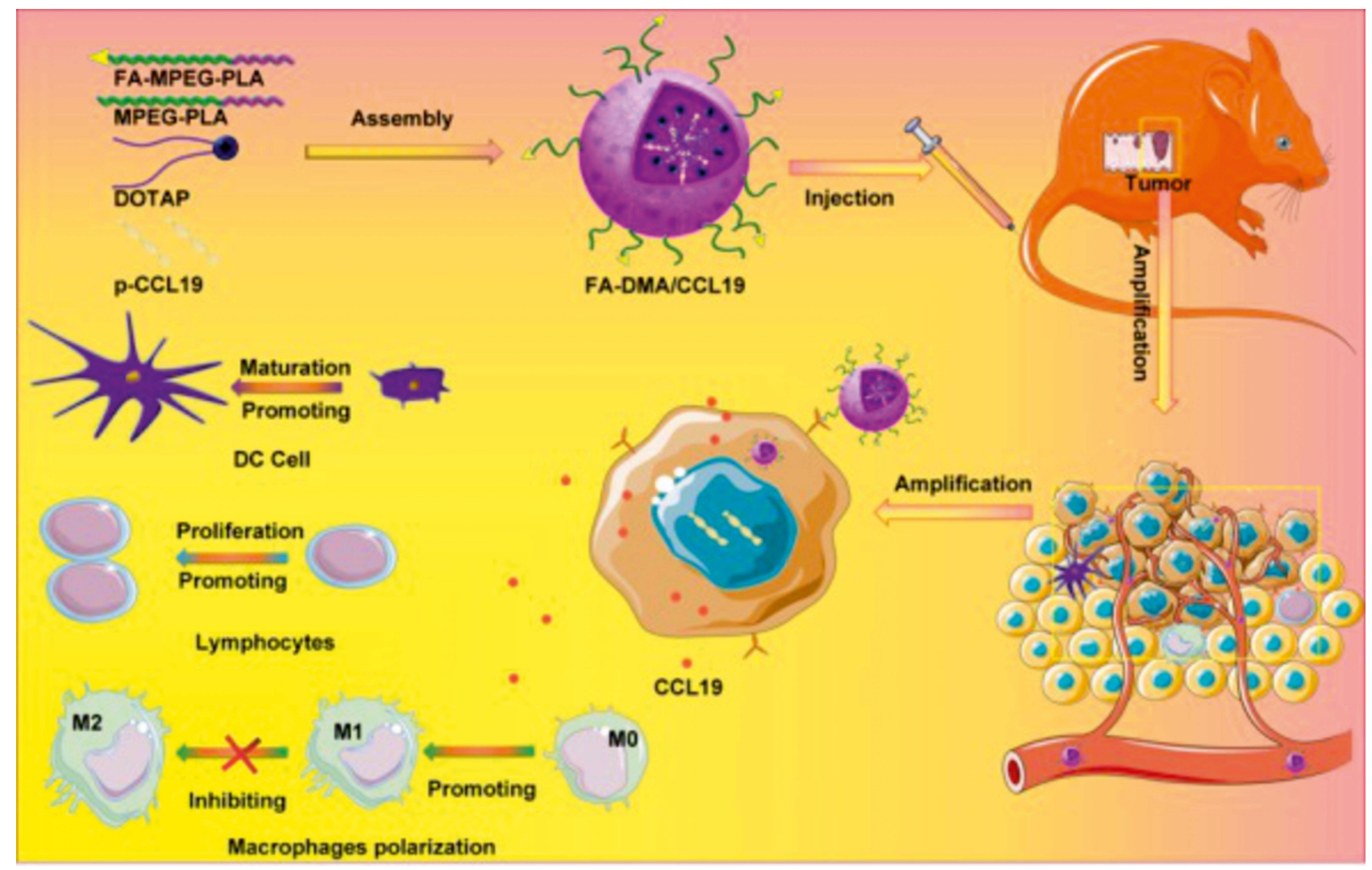

Figure 4 Schematic illustration of the effects of the folate targeted gene-delivery system consisting of methoxy poly(ethylene glycol)-poly(lactide) (MPEG-PLA) and DOTAP loaded with CCLI9 (FA-DMA/CCLI9). The gene delivered into tumor cells expresses and secrets CCLI9 protein factor, which induced activation of the immune system to kill cancer.

Notes: Reprinted with permission from Liu X, Wang B, Li Y, et al. Powerful Anticolon Tumor Effect of Targeted Gene Immunotherapy Using Folate-Modified Nanoparticle Delivery of CCL19 To Activate the Immune System. ACS Cent Sci. 2019;5:277-289 (https://pubs.acs.org/doi/10.1021/acscentsci.8b00688). ${ }^{95}$ Copyright (2019) American Chemical Society. Further permissions related to the material excerpted should be directed to the ACS. 
and reducing proliferation through activation of the host immune system. ${ }^{96,97}$

An amphiphilic cationic tri-arm star copolymer which comprises hydrophilic poly(ethylene oxide) (PEO), hydrophobic PLA, and a cysteine-terminated polylysine block $(\mathrm{CKn})$ with a cleavable disulfide linkage, all coupled through a serine (S) core was synthesized by a combination of ring opening polymerization (ROP) and a thiol-disulfide exchange. The PEO-S(CKn)-PLA system was employed to study the DNA condensation ability at different $\mathrm{N} / \mathrm{P}$ ratios (ratios of $\mathrm{N}$ atoms in CKn blocks to $\mathrm{P}$ atoms in the plasmid DNA). In vitro DNA transfection studies pointed out that the amphiphilic star copolymer is able to induce DNA transfection and GFP expression, without cytotoxicity. ${ }^{98}$

The co-delivery of paclitaxel (PTX) and survivin siRNA was realized for lung cancer therapy by a pH-responsive polymeric carrier composed of cationic PEI-PLA NPs coated with a negatively charged PEGblock-poly(l-aspartic acid sodium salt) (PEG-PAsp). Survivin is an antiapoptotic protein overexpressed in many cancer tissues, including non-small cell lung cancer, and its inhibition caused by siRNA transfection with PEIPLA/PTX/siRNA/PEG-PAsp NPs promotes apoptosis, suppresses cancer cell proliferation and significantly increased the PTX-induced cell death, leading to a synergistic antitumor effect. ${ }^{29}$

A useful strategy, as an alternative to the employment of traditional cationic nanocarriers, to improve the inherent features of siRNA molecules (i.e. negative charge and hydrophilic nature) was the mixing of siRNA with doxorubicin hydrochloride (DOX $\cdot \mathrm{HCl})$ to achieve siRNA hydrophobization driven by electrostatic interactions. ${ }^{99}$ The resulting hydrophobic [siRNA and DOX] complex was efficiently encapsulated into non-cationic PEG-PLA micelles for systemic delivery. The NPs had excellent colloidal stability, encapsulation efficacy of $41.16 \pm$ $0.47 \%$, a size of $53 \pm 5.7 \mathrm{~nm}$ and a zeta potential of approximately $-13.2 \mathrm{mV}$. The silencing efficacy was evaluated in MDA-MB-231 cancer cells incubated with [siRNA and DOX]-loaded NPs, at different siRNA concentrations, and the expression of polo-like kinase 1 (Plk1), as the oncogenic target gene, at the mRNA and protein levels was analyzed. The treatment with NPs loaded with [siPlk1 and DOX] induced a dose-dependent gene silencing in Plk1 protein expression; this dosedependent downregulation of Plk1 expression finally induces cancer cell apoptosis. The present combination of siRNA therapy and chemotherapy was successful also in vivo in MDA-MB-231 xenograft murine model following intravenous injection. This strategy could be extended to deliver other hydrochloride forms of anticancer drugs with large hydrophobic domains and it is also applicable to plasmid DNA, mRNA, miRNA, providing a versatile strategy for combined gene and drug delivery. ${ }^{99}$

\section{CRISPR/Cas Formulations Based on PLGA and PLA Nanoparticles}

CRISPR/Cas9 is an emerging genome-editing tool with unprecedented potential for the treatment of several diseases. ${ }^{5}$ It consists in two main components: (i) an RNA guided-endonuclease (Cas9) that can produce blunt-end cleavage at specific sites of DNA complementary to sgRNA; (ii) a hybrid RNA (sgRNA) which contains the complementary sequences to the target DNA (crRNA) and a non-variable sequence (tracrRNA) for the hybridization with crRNA. ${ }^{100}$ The delivery of CRISPR/ Cas9 components by viral vectors has been widely explored due to its high efficiency, although this technology is often related to drawbacks, such as mutagenesis, immunogenicity, and off-target effects. Currently non-viral vectors, including polymers, liposomes, cell-penetrating peptides, and other synthetic vectors, are extensively investigated to deliver CRISPR/Cas9. Many factors should be considered in the selection of the transfection method, including efficiency, lifetime expression and ability to cross both the cell membrane and the nuclear membrane. The CRISPR/Cas9 system can be delivered by three different formats (Figure 5), including: the delivery of pDNA, which encodes Cas9, and sgRNA (Figure 5, format a); the delivery of mRNA and sgRNA (Figure 5, format b); the delivery of Cas9 protein complexed with sgRNA (ribonucleoprotein, RNP; Figure 5, format c). The pDNA delivery is an inexpensive method generating stable Cas9 nucleases, but it is associated with some disadvantages, such as the persistent expression, generating off-target effects at undesired genome sites, and the large size of some plasmids that could present difficulty in the packaging into the vector. Plasmid enters the nucleus expressing the corresponding protein components by transcription and translation (Figure 5, format a). The delivery of RNP and mRNA (Figure 5, format $\mathrm{b}$ and $\mathrm{c}$ ), due to their relatively short half-life, overcomes the safety limitation of pDNA delivery, preserving the gene-editing ability. ${ }^{101}$ The translation of mRNA into Cas9 protein occurs in the ribosome 


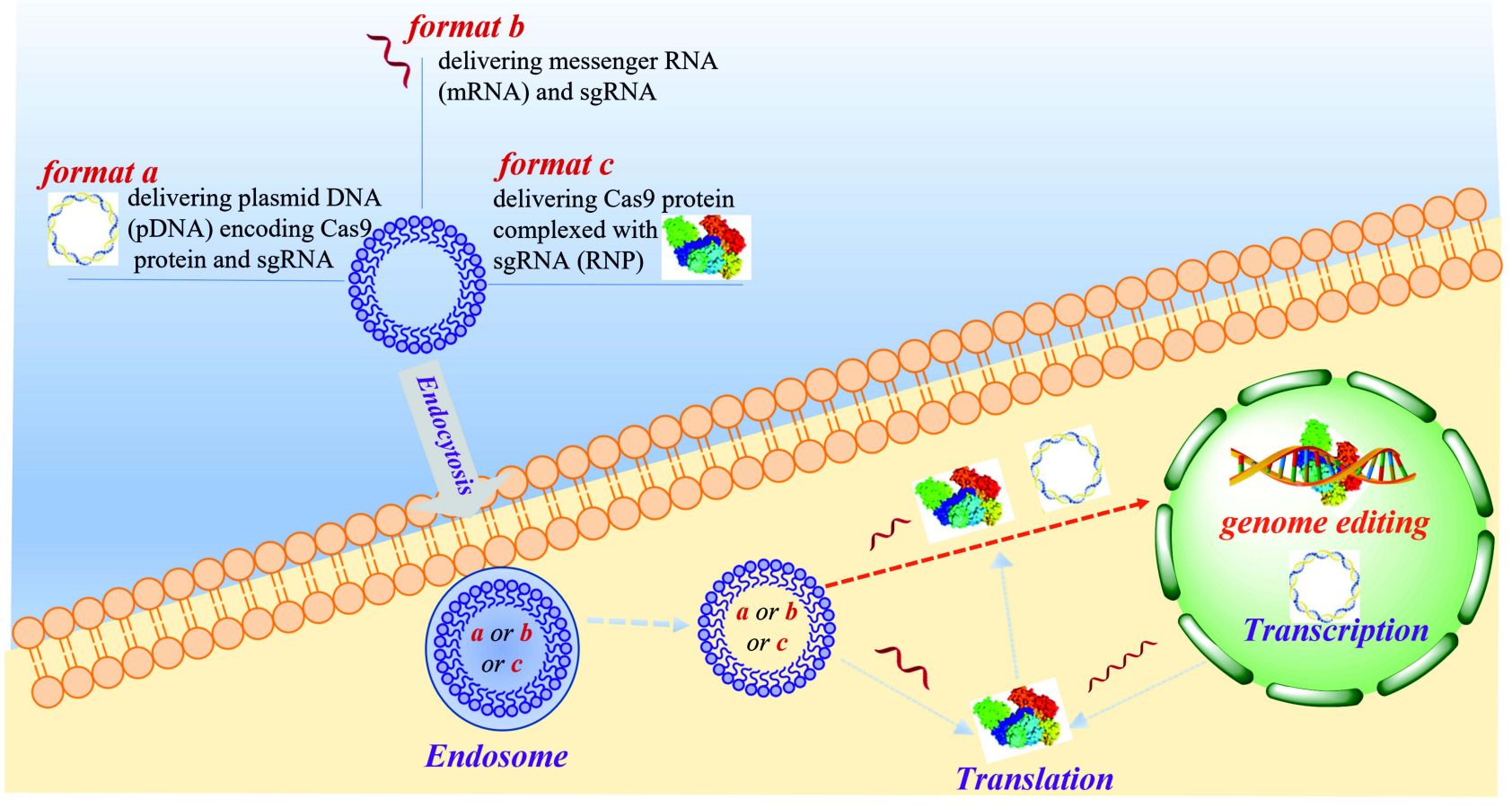

Figure 5 Schematic representation of different configurations of Cas9/sgRNA elements used in the intracellular delivery: format a delivers plasmid DNA encoding Cas 9 proteins and sgRNA; format b delivers mRNA and sgRNA; format c delivers Cas9 protein complexed with sgRNA (ribonucleoprotein RNP).

avoiding the nuclear entry; this requires the simultaneous loading of mRNA and sgRNA into the carrier (Figure 5, Format $\mathrm{b}$ ), hence formulation and storage might be challenging, due to mRNA lability. The delivery of RNP (Figure 5, format c), bypassing the transcription and translation processes, generates the fastest gene-editing effect. Moreover, a protective effect of Cas9 proteins to sgRNA producing stable RNP has been reported in literature. ${ }^{102}$

So far, only a few polymer-based carriers have demonstrated promising ability to deliver plasmid encoding Cas9 and sgRNA. In this context, the main strategy relies on the "CLAN nanomedicine" that consists in the NA inclusion into the inner core of polymeric nanosystems by double emulsion procedure assisted by cationic lipids, such as BHEM-Chol. ${ }^{30,85}$ CLAN preparation includes a primary emulsification step in which NA and the cationic lipids assemble into tight complexes at the water-oil interface and a second emulsification step which allows the encapsulation of complexes into the inner aqueous core of PEG-PLA or PEG-PLGA NPs (Figure 6A). ${ }^{85}$ Being NA encapsulated in the core, the PEG surface prevents their degradation by nucleases or their recognition by the immune system. Moreover, PEG stabilizes CLAN by preventing aggregation, protein adsorption, and protects CLAN from opsonization thanks to its stealth ability. ${ }^{103}$ Macrophage-specific CD68 promoter-driven Cas9 expression plasmids (pM330 and pM458) encapsulated into PEG-PLGA-based CLAN were proposed as a delivery strategy for cell-specific genome editing since the expression of Cas9 protein occurs only in macrophages and monocytes instead of other cell lines (Figure 6A-C). ${ }^{85}$

The same type of CLAN carriers was exploited to deliver Cas9 mRNA and sgRNA targeting NLRP3, a major mediator of acute/chronic inflammation. ${ }^{104}$ The CLANmCas9/gNLRP3 delivery system was proposed to disrupt NLRP3 locus into macrophages. Experimental results indicated that CLAN with a higher surface charge and lower PEG density were more efficiently internalized by macrophages. Moreover, Cas9/gNLRP3 RNA encapsulated in CLAN were protected from RNase of the physiological environment and the Cas9 protein expression was detected within several hours after transfection. However, CLANmCas9/gNLRP3 did not completely inactivate the NLRP3 inflammasome, probably due to a moderate transfection efficiency. ${ }^{104}$

CLAN carrying the CRISPR/Cas9 system was proposed as a promising strategy for reprogramming DCs to abate transplant rejection. ${ }^{105}$ Cas9 mRNA (mCas9) and a guide RNA targeting the costimulatory molecule CD40 (gCD40) were delivered into DCs using CLAN as a vector. 


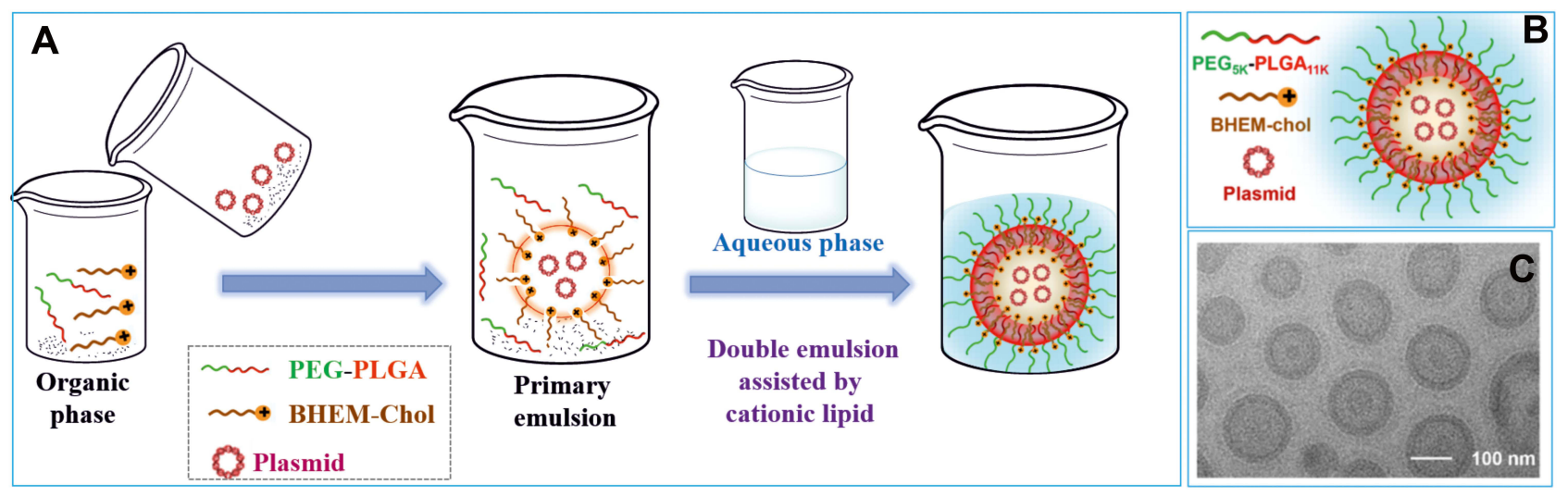

Figure 6 (A) Schematic representation of Cationic Lipid Assisted Nanoparticles (CLAN) preparation by double emulsion solvent evaporation method. (B) CLAN vector

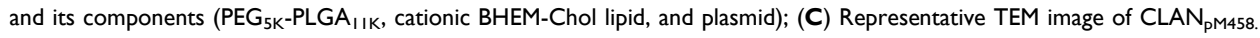

Notes: Panels B and C reprinted with permission from Luo YL, Xu CF, Li HJ, et al. Macrophage-Specific in Vivo Gene Editing Using Cationic Lipid-Assisted Polymeric Nanoparticles. ACS Nano. 2018;12:994-1005. ${ }^{85}$ Copyright (2018) American Chemical Society.

After intravenous injection into an acute mouse skin transplant model, CLANmCas9/gCD40 released $\mathrm{mCas} 9 / \mathrm{gCD} 40$ into DCs and disrupted CD40 at the genomic level, both in vitro and in vivo, with a significant inhibition of $\mathrm{T}$ cell activation. $^{105}$ Recently, Wank and coworkers utilized CLAN for the simultaneous co-encapsulation of an autoimmune diabetes-relevant peptide (2.5mi), a CRISPRCas9 plasmid (pCas9), and three sgRNA targeting costimulatory molecules (CD80, CD86, and CD40). ${ }^{106}$ The proposed all-in-one nanomedicine was able to effectively co-deliver these components into DCs, in vitro and in vivo, followed by knockout of the three costimulatory molecules and presentation of the $2.5 \mathrm{mi}$ peptide on DCs surfaces. CLANpCas9/gCD80,86,40/2.5mi treatment effectively restored autoantigen-specific immune tolerance, inhibited insulitis and inflammation in NOD/Ltj mice with spontaneous autoimmune diabetes.

The delivery of the RNP complex (Figure 5 format c) is the most straightforward method for genome editing. RNP is a negative complex of about $10 \mathrm{~nm}$, consisting of both a positively charged Cas (22 positive charges) and a negatively charged sgRNA (about 100 negative charges). RNP was delivered both in vitro and in vivo using RNP packaging carriers that exploited electrostatic interactions, such as dendrimers, PBAEs, PLL, and chitosan NPs. ${ }^{103,107}$

Up to now, no polyester-based NPs have been developed for RNP delivery and transfection.

The rapid worldwide spread of COVID-19 has led to a public health crisis of an unprecedented scale since the beginning of 2020. The global efforts to discover new diagnostic and therapeutic solutions to tackle the pandemic have involved also the revolutionary CRISPR/Cas system of genome editing. Firstly, CRISPR technology has been successfully used to develop rapid diagnostic devices for COVID-19. ${ }^{108,109}$ Recently, the CRISPR/Cas13 system has been proposed for the cleavage of the viral RNA genome inside the infected cells or for prevention of the expression of protein-coding genes of the virus. Cas13 nuclease cleaves single-strand RNA (ssRNA) rather than double-strand DNA (dsDNA), a promising result for gene knockdown applications. The CRISPR-Cas13 based therapy called Prophylactic Antiviral CRISPR in the huMAN cells (PAC-MAN-T6) was proposed for the first time by Abbott et al. ${ }^{110}$ Different locations of SARS-CoV-2 RNA genome (i.e. NSP1-NSP16, accessory proteins, and ORF110) have been identified as targets for CRISPR/Cas13based therapy. However, some potential off-target effects and the challenge of delivery in mammalian cells are the main hindrances for the therapeutic use of CRISPR/Cas13 against COVID-19. To the best of our knowledge, no polymeric carriers have been investigated for antiviral CRISPR/Cas 13 therapy so far and the current investigated transfection methods consist in lipofection, electroporation, nucleofection, microinjection, and viral vectors. ${ }^{111}$

\section{COVID- 9 mRNA Vaccine: Nanotechnology's Role for a Global Race}

The SARS-CoV-2 pandemic has set off an international need to develop innovative approaches for COVID-19 management and treatment. Current interventions include vaccines, ${ }^{9,11,63}$ therapies targeting the CoV's life cycle, 
either blocking cell entry or inhibiting the viral cycle within the host cell, ${ }^{112,113}$ and therapies to target the immune response. ${ }^{114}$ Despite considerable global efforts and over 300 active clinical evaluations, no effective drugs exist, so far, to combat the pandemic. In this scenario, the pivotal role of nanotechnology in developing groundbreaking mRNA-vaccines delivered by NPs, has emerged wordwide, pushing the boundaries of gene therapy, enabling a swift response to the COVID-19 pandemic. Currently, two forms of nanotechnology-based mRNA vaccines have been explored: conventional mRNA and self-amplifying mRNA derived from the genome of positive-stranded RNA viruses. Conventional mRNA-based vaccines encode the antigen of interest and contain untranslated regions from $5^{\prime}$ and $3^{\prime}$; whereas selfamplifying RNAs encode viral replication mechanism in addition to viral antigen permitting intracellular RNA amplification and profuse protein synthesis. ${ }^{115}$ Both approaches share essential elements of a eukaryotic mRNA: a cap structure [m7Gp3N ( $\mathrm{N}$, any nucleotide)], a 50 UTR, an open reading frame (ORF), a 30 UTR, and a tail of 40-120 adenosine residues [poly(A) tail]. The self-amplifying mRNA vaccines are able to direct their self-replication through the synthesis of the RNAdependent RNA polymerase complex, generating multiple copies of the antigen-encoding mRNA. Thus, it is possible to express high levels of the heterologous gene when they are properly delivered into the cytoplasm of host cells. The acquired capability of the mRNA vaccines to mimic the production of viral pathogens-antigens in vivo trigger both host humoral and cellular immune responses. Both the mRNA vaccines which received Emergency Use Authorization for COVID-19 (BioNTech/Pfizer and Moderna) employ LNPs as a carrier which also act as an adjuvant. The nanocapsule included four lipids (cationic lipids, cholesterol, PEGylated lipids, and phospholipids) formulated in a fixed ratio with mRNA. Cationic lipids assist the incorporation of negatively charged mRNA, phospholipids and cholesterol contribute to the NPs structure, the PEG component stabilizes LNPs prolonging their lifespan, even if some researchers speculate that it could be responsible for occasional allergic side effects. ${ }^{116}$ The nanocarrier encapsulating mRNA shields it from enzymatic degradation, assure an efficient cellular uptake and shuttles it into cells, where the mRNA encodes the spike (S) protein of SARS-CoV-2. Specifically, mRNA vaccine developed by BioNTech/Pfizer (Comirnaty) consists in mRNA encapsulated in $80 \mathrm{~nm}$ ionizable LNPs targeting the receptor-binding domain (RBD) of the $\mathrm{S}$ protein of SARS-CoV-2; it elicits high neutralizing titers as well as Th1-based CD4+ T-cell responses. ${ }^{117-119}$ Moderna mRNA-1273 vaccine consists in a synthetic viral mRNA encoding for a stable form of the $\mathrm{S}$ protein encapsulated in LNPs. ${ }^{120}$ mRNA encodes the S-2P antigen, consisting of the SARS-CoV-2 glycoprotein with a transmembrane anchor and an intact S1-S2 cleavage site. S-2P is stabilized in its prefusion conformation by two consecutive proline substitutions at amino acid positions 986 and 987, at the top of the central helix in the S2 subunit. ${ }^{118}$

Currently, self-assembly represents the main approach for the preparation of most of the non-viral vectors for mRNA delivery, including a large fraction of mRNA vaccines. ${ }^{121}$ Self-assembly is an important concept in material science and it entails the formation of supramolecular architectures by a spontaneous arrangement of individual building blocks driven by noncovalent interactions. The mixing of mRNA and the encapsulating materials is often carried out by microfluidic mixers to obtain controlled and reproducible lots. The recent advances in microfluidic technology can allow for scale-up with the precision that is required for Good Manufacturing Practice (GMP) facilities. ${ }^{121,122}$ mRNA vaccines formulated in LNPs have enabled a swift response to the pandemic, but issues of stability, currently mitigated by an ultra-cold chain, and the related production cost pose a major hurdle for effective and equitable distribution. To overcome these drawbacks, other nanocarriers including protamine nanoliposomes, PEG-lipid functionalized dendrimers, positively charged oil-in-water cationic nanoemulsions, and cationic polymer (chitosan, PEI, etc.) NPs are investigated, although to the best of our knowledge, no examples are under clinical development. ${ }^{123}$

In the past, native PLGA was studied as a delivery vehicle for DNA vaccine; however, some weaknesses such as the acidification of the microenvironment upon its degradation and the attenuation of immunogenicity of delivered vaccines limited its application in this field. ${ }^{124}$ The combination of PLGA with other polymers, such as cationic glycol-chitosan/PLGA and PEI/PLGA, was proposed to improve the stability of the formulation and the performance of transfection of DNA vaccines. Although vaccine carriers based on PLGA are still confined in the laboratory arena, ${ }^{125}$ the fundamental delivery attributes of polyesterbased NPs, including their ability to integrate multiple potent antigens or antigen-encoding NA, co-deliver appropriate costimulatory molecules, and target specific immune 
cells could be useful to induce the well-orchestrated immunity required for an efficient and prolonged protection against SARS-CoV-2 and other viral infection-related respiratory injuries. ${ }^{126-128}$ Polyester-based NPs and cationic lipid-assisted nanoparticles may still find a key role in future vaccines, paying special attention to the fundamental formulation aspects that would guarantee a good encapsulation efficiency, cargo stability, optimal size and shape. Moreover, nanoparticles' lyophilization or other drying approaches would offer great advantages in terms of longterm stability of the vaccines.

Beside the two mentioned mRNA vaccines, the management of the pandemic currently benefits from other effective vaccines, that we report in Table 1, pointing out that mass immunization through vaccination represents the highest priority for the control of the SARS-CoV-2 pandemic. ${ }^{116,120,129}$

\section{Conclusion and Future Perspectives}

Non-viral gene delivery vehicles, including poly(lactic-coglycolic acid) and polylactic acid NPs, have been developed to mitigate the side-effects associated with viral delivery carriers, which have a history of safety concerns. In this review, we have discussed the recent advances in the application of polyester-based NPs for the delivery of different types of nucleic acids (e.g. siRNA, mRNA, plasmid DNA, and the revolutionary genome editing machinery CRISPR/Cas), pointing out their excellent biocompatibility and biodegradability, low immunogenicity and easily tailored properties. Safety and biocompatibility of polyester-based nanovehicles are merits that have been assessed in the long term, differently from other emergent nanomaterials proposed for gene delivery, including graphene and carbon nanotubes, whose impact on cell biology still seems partially and fragmentally elucidated. PLGA- and PLA-based NPs are prone to efficiently promote a sustained delivery of foreign nucleic acids to the target tissue, protecting them from enzymatic degradation and immune recognition, improving plasma half-life and cellular uptake and assisting the nucleic acid in escaping from renal and hepatic clearance. They turned out to be able to overcome the limitations of free therapeutics and navigate biological barriers (e.g. systemic, microenvironmental and cellular) that are heterogeneous across patient populations and diseases. The versatile engineering of NPs surface influences solubility, aggregation features, ability to cross physiological barriers, intracellular trafficking, targeting properties, inherent responsiveness to the intracellular environment and release profile.
An intelligent NPs design allows to improve payload delivery, enhancing the performance of precision medicine therapies, thus accelerating their clinical translation. Furthermore, the use of PLGA and PLA NPs enables to effectively combine various therapeutics (e.g. small molecule drugs and NA) and treatment modalities, overcoming the limitations of existing therapies and the multidrug resistance often associated with cancer treatment. Although most of the polyester-based delivery systems are still in the lab-scale, their potentialities could be explored as an avenue of enhancing gene therapeutics production and their clinical applications.

We also believe that further research into the delivery potential of PLGA and PLA nanocarriers for vaccines development is warranted due to their biocompatibility, size consistency, colloidal stability, tunable adjuvant loading, $\mathrm{pH}$ responsive release, and antigen functionalizability. Although oncology was the major area where nanotechnological drug carriers had been widely explored before the COVID-19 crisis, nowadays the mRNA vaccines formulated with lipid-based NPs represent the stepping stone for the future of both nanomedicine and gene therapy.

\section{Abbreviations}

NA, nucleic acid; NPs, nanoparticles; PLGA, lactic-coglycolic acid; PLA, polylactic acid; siRNA, short interfering RNA; mRNA, messenger RNA; pDNA, plasmid DNA; CRISPR/Cas, clustered, regularly-interspaced, short palindromic repeats/Cas; COVID-19, Coronavirus Disease 2019; miRNA, microRNA; LNPs, lipid-based nanoparticles; TTR, transthyretin; sgRNA, single guide RNA; CLAN, Cationic Lipid-Assisted Nanoparticles; PEG-PLA, poly(ethylene glycol)/polylactic acid; PEGPLGA poly(ethylene glycol)/poly(lactic-co-glycolic acid); RISC, RNA-Induced Silencing Complex; GalNAc, N-AcetylGalactosamine; shRNA, short stranded RNA; lncRNA, long non-coding RNA; PRC2, polycomb repressive complex 2; RA, rheumatoid arthritis; UTR, untranslated region; PEI, polyethylenimine; PBAEs, poly $(\beta-$ amino)esters; CARTs, charge altering releasable transporters; APEs, amino-polyesters; TALE, transcription activator-like effector; PLL, poly(L-lysine); DOTAP/Chol, 1,2 dioleolyl-3-N,N,N,-trimethylammonium-propane/cholesterol; DOTMA, N-(1-(2,3-dioleoyloxy)propyl)-N,N, $\mathrm{N}$-trimethylammonium; OVs, oncolytic viruses; W/O/W, water-oil-water; pDMAEMA, poly(2-dimethylamino)ethyl methacrylate; DC-Chol, dimethylaminoethane carbamoyl cholesterol; CCCP, cationic cell-penetrating peptide; 
Table I Overview of COVID-I9 Vaccines Licensed or Under Development

\begin{tabular}{|c|c|c|c|}
\hline Vaccine Target & Name & $\begin{array}{l}\text { Delivery System/ } \\
\text { Formulation }\end{array}$ & Status \\
\hline \multirow[t]{3}{*}{$\begin{array}{l}\text { Inactivated virus vaccines, which use } \\
\text { inactivated or weakened virus to generate an } \\
\text { immune response without disease }\end{array}$} & PiCoVace & $\begin{array}{l}\text { Inactivated } \\
\text { SARS-CoV-2 } \\
+ \text { alum adjuvant }\end{array}$ & Clinical trial ongoing \\
\hline & $\begin{array}{l}\text { Sinovac } \\
\text { (Sinovac and } \\
\text { Instituto } \\
\text { Butatan) } \\
\text { (known as } \\
\text { CoronaVac) }\end{array}$ & $\begin{array}{l}\text { Inactivated } \\
\text { SARS-CoV-2 } \\
+ \text { alum adjuvant }\end{array}$ & $\begin{array}{l}\text { Approved in China and Bahrain. Emergency } \\
\text { use in other countries }\end{array}$ \\
\hline & $\begin{array}{l}\text { Sinopharm } \\
\text { (BBIBP-CorV) }\end{array}$ & $\begin{array}{l}\text { Inactivated virus produced } \\
\text { in Vero cells }\end{array}$ & $\begin{array}{l}\text { Approved in China. } \\
\text { Emergency use in other countries }\end{array}$ \\
\hline $\begin{array}{l}\text { Vaccines Based on Full-Length S Protein } \\
\text { to generate an immune response }\end{array}$ & $\begin{array}{l}\text { Novavax } \\
(\text { NVX- } \\
\text { CoV2373) }\end{array}$ & $\begin{array}{l}\text { Spontaneous NPs formation; } \\
\text { it contains a saponine-based } \\
\text { adjuvant }\end{array}$ & Under review by EMA and FDA \\
\hline $\begin{array}{l}\text { Protein Subunit Vaccine (RBD-Based vaccine) } \\
\text { RBD of SARS-CoV-S contains major antigenic } \\
\text { epitopes }\end{array}$ & $\begin{array}{l}\text { NCT } 04473690 \\
\text { (Kentucky } \\
\text { Bioprocessing } \\
\text { Inc.) }\end{array}$ & $\begin{array}{l}\text { Recombinant antigenic } \\
\text { proteins that induce both } \\
\text { neutralizing antibodies and } \\
T \text { cell responses }\end{array}$ & $\begin{array}{l}\text { I and II } \\
\text { clinical trials (NCT04473690) }\end{array}$ \\
\hline \multirow[t]{4}{*}{$\begin{array}{l}\text { Viral vector vaccines, which use non- } \\
\text { replicating viral vector as platform to produce } \\
\text { coronavirus proteins to generate an immune } \\
\text { response }\end{array}$} & $\begin{array}{l}\text { Vaxzevria } \\
\text { Oxford/ } \\
\text { AstraZeneca } \\
\text { (AZDI222) }\end{array}$ & $\begin{array}{l}\text { Chimpanzee Ad (ChAdOxl) } \\
\text { expressing the gene of } \\
\text { S protein }\end{array}$ & $\begin{array}{l}\text { Approved in Brazil. } \\
\text { Emergency use in the UK, EU, other } \\
\text { countries. Stopped use in Denmark. }\end{array}$ \\
\hline & $\begin{array}{l}\text { Gam-COVID- } \\
\text { Vac (Sputnik V) }\end{array}$ & $\begin{array}{l}\text { Modified Ad26 and Ad5 } \\
\text { viruses containing the gene } \\
\text { for S protein }\end{array}$ & Approved in Russia; under review by EMA \\
\hline & $\begin{array}{l}\text { Janssen } \\
\text { (Johnson \& } \\
\text { Johnson) } \\
\text { (JNJ-78436735) }\end{array}$ & $\begin{array}{l}\text { Recombinant, replication- } \\
\text { incompetent Ad26 } \\
\text { expressing the S protein }\end{array}$ & FDA/ EMA approved \\
\hline & $\begin{array}{l}\text { Ad5-nCoV } \\
\text { CanSinoBio }\end{array}$ & $\begin{array}{l}\text { Recombinant Novel } \\
\text { Coronavirus Vaccine } \\
\text { (Adenovirus Type } 5 \text { Vector) }\end{array}$ & \\
\hline \multirow{3}{*}{$\begin{array}{l}\text { RNA vaccines: is a cutting-edge approach that } \\
\text { uses genetically engineered RNA to generate } \\
\text { a protein that itself safely prompts an immune } \\
\text { response }\end{array}$} & $\begin{array}{l}\text { Comirnaty } \\
\text { (BioNTech/ } \\
\text { Pfizer) }\end{array}$ & Lipid NPs & FDA/ EMA approved \\
\hline & Moderna & Lipid NPs & FDA/ EMA approved \\
\hline & $\begin{array}{l}\text { CureVac } \\
(\mathrm{CVnCoV} \\
\text { vaccine })\end{array}$ & Lipid NPs & $\begin{array}{l}\text { Results of phase } 2 b / 3 \text { (June } 202 \mathrm{l} \text { ) indicated an } \\
\text { efficacy of } 47 \% \text { in symptomatic disease, lower } \\
\text { than } 50 \% \text { and } 70 \% \text { efficacy requested by the } \\
\text { FDA and OMS, respectively. }{ }^{130,131}\end{array}$ \\
\hline
\end{tabular}

(Continued) 
Table I (Continued).

\begin{tabular}{|l|l|l|l|}
\hline Vaccine Target & Name & $\begin{array}{l}\text { Delivery System/ } \\
\text { Formulation }\end{array}$ & Status \\
\hline $\begin{array}{l}\text { DNA vaccines which use plasmid DNA to } \\
\text { generate a protein that prompts an immune } \\
\text { response }\end{array}$ & $\begin{array}{l}\text { AG030I- } \\
\text { COVIDI9 } \\
\text { (AnGeslnc) }\end{array}$ & $\begin{array}{l}\text { Plasmid encoding } \\
\text { S protein }\end{array}$ & Phase I/2 \\
\cline { 2 - 5 } & $\begin{array}{l}\text { INO-4800 } \\
\text { (Inovio } \\
\text { Pharmaceuticals) }\end{array}$ & DNA with electroporation & $\begin{array}{l}\text { Phase 2-3 (USA) } \\
\text { (NCT04642638) }\end{array}$ \\
\hline
\end{tabular}

pGFP: green fluorescent protein encoding plasmid; HEK 293, human embryonic kidney 293 cell line; RA, retinoic acid; QDs, quantum dots; FA, folic acid; RGD, arginylglycylaspartic acid; IKVAV, isoleucine-lysine-valinealanine-valine; PC12, rat pheochromocytoma cell line; HCC, hepatocellular carcinoma; TK-p53-NTR, thymidine kinase-p53-nitroreductase plasmid; GDEPT, genedirected enzyme-prodrug therapy; GCV, ganciclovir; US, ultrasound; MB, microbubble; TNBC, triple-negative breast cancer; Gpc3, glypican-3; ARC, apoptosis repressor with caspase recruitment domain; CTAB, cetyltrimethylammonium bromide; DMAB, didodecyldimethylammonium bromide; CLSM, confocal laser scanning microscopy; FACS, fluorescence-activated cell sorting; BTK, Bruton's tyrosine kinase; BHEM-Chol, N,N-bis (2-hydroxyethyl)-N-methyl-N-(2-cholesteryloxycarbonyl aminoethyl) ammonium bromide; OVA, ovalbumin; DCs, dendritic cells; TLR, Toll-like receptors; SLA, solubleantigen of Leishmania; iNOS, inducible nitric oxide synthase; RBC, red blood cell; bFGF, basic fibroblast growth factor; VEGFA, vascular endothelial growth factor A; PDGF-B, platelet derived growth factor; DFU, diabetic foot ulceration; IL15, interleukin-15; IL-12, interleukin12; PEO, poly(ethylene oxide); ROP, ring opening polymerization; PTX, paclitaxel; PEG-PAsp, PEG-block-poly (l-aspartic acid sodium salt); DOX $\cdot \mathrm{HCl}$, doxorubicin hydrochloride; Plk1, polo-like kinase 1; RNP, ribonucleoprotein; ssRNA, single-strand RNA; dsDNA, doublestrand DNA; ORF, open reading frame; S, spike protein; RBD, receptor-binding domain; GMP, Good Manufacturing Practice.

\section{Acknowledgments}

This review article was partially supported by the grant FFABR_2017_ Fondo Finanziamento Attività Base Ricerca 2017_SCALA_ANGELA.

\section{Disclosure}

The authors report no conflicts of interest in this work.

\section{References}

1. Sung Y, Kim S. Recent advances in the development of gene delivery systems. Biomater Res. 2019;23:8.

2. Weng Y, Huang Q, Li C, et al. Improved nucleic acid therapy with advanced nanoscale biotechnology. Mol Ther Nucleic Acids. 2020;19:581-601.

3. Weng Y, Xiao H, Zhang J, Liang X-J, Huang Y. RNAi therapeutic and its innovative biotechnological evolution. Biotechnol Adv. 2019;37:801-825.

4. Weng $\mathrm{Y}$, Li C, Yang $\mathrm{T}$, et al. The challenge and prospect of mRNA therapeutics landscape. Biotechnol Adv. 2020;40:10 7534.

5. Li H, Yang Y, Hong W, Huang M, Wu M, Zha X. Applications of genome editing technology in the targeted therapy of human diseases: mechanisms, advances and prospects. Signal Transduct Target Ther. 2020;5:1.

6. Wong JKL, Mohseni R, Hamidieh AA, MacLaren RE, Habib N, Seifalian AM. Will nanotechnology bring new hope for gene delivery? Trends Biotechnol. 2017;35:434-451. doi:10.1016/j. tibtech.2016.12.009

7. Bulcha JT, Wang Y, Ma H, et al. Viral vector platforms within the gene therapy landscape. Sig Transduct Target Ther. 2021;6:53.

8. Wolf J, Bruno S, Eichberg M, et al. Applying lessons from the Ebola vaccine experience for SARS-CoV-2 and other epidemic pathogens. Npj Vaccines. 2020;5:51. doi:10.1038/s41541-0200204-7

9. Pushparajah D, Jimenez S, Wong S, Alattas H, Nafissi N, Slavcev RA. Advances in gene-based vaccine platforms to address the COVID-19 pandemic. Adv Drug Del Rev. 2021; 170:113-141.

10. Yang D. Application of nanotechnology in the COVID-19 pandemic. Int J Nanomed. 2021;16:623-649. doi:10.2147/IJN. S296383

11. Park KS, Sun X, Aikins ME, Moon JJ. Non-viral COVID-19 vaccine delivery systems. Adv Drug Deliv Rev. 2021;16 9:137-151. doi:10.1016/j.addr.2020.12.008

12. Urits I, Swanson D, Swett MC, et al. A review of patisiran $\left(\right.$ ONPATTRO $\left.^{\circledR}\right)$ for the treatment of polyneuropathy in people with hereditary transthyretin amyloidosis. Neurol Ther. 2020;9:301-315. doi:10.1007/s40120-020-00208-1

13. Hu B, Zhong L, Weng Y, et al. Therapeutic siRNA: state of the art. Sig Transduct Target Ther. 2020;5:101.

14. Wang Y, Bruggeman KF, Franks S. Is viral vector gene delivery more effective using biomaterials? Adv Healthc Mater. 2021;10:2001238. doi:10.1002/adhm.202001238 
15. Rai R, Alwani S, Badea I. Polymeric nanoparticles in gene therapy: new avenues of design and optimization for delivery applications. Polymers. 2019;11:745. doi:10.3390/polym11040 745

16. Caccamo D, Currò $M$, Ientile $R$, et al. Intracellular fate and impact on gene expression of doxorubicin/cyclodextrin-graphene nanomaterials at sub-toxic concentration. Int $J$ Mol Sci. 2020;21:4891. doi:10.3390/ijms21144891

17. Piperno A, Mazzaglia A, Scala A, et al. Casting light on intracellular tracking of a new functional graphene-based microrna delivery system by FLIM and raman imaging. ACS Appl Mater Interfaces. 2019;11:46101-46111. doi:10.1021/acsami.9b15826

18. Mazzaglia A, Scala A, Sortino G, et al. Intracellular trafficking and therapeutic outcome of multiwalled carbon nanotubes modified with cyclodextrins and polyethylenimine. Colloids Surf B Biointerfaces. 2018;163:55-63. doi:10.1016/j.colsurfb.2017. 12.028

19. Elmowafy EM, Tiboni M, Soliman ME. Biocompatibility, biodegradation and biomedical applications of poly(lactic acid)/poly (lactic-co-glycolic acid) micro and nanoparticles. J Pharm Investig. 2019;49:347-380. doi:10.1007/s40005-019-00439-x

20. Scala A, Piperno A, Micale N, et al. "Click" on PLGA-PEG and hyaluronic acid: gaining access to anti-leishmanial pentamidine bioconjugates. $J$ Biomed Mater Res B Appl Biomater. 2018;106:2778-2785.

21. Fazio E, Scala A, Grimato S, Ridolfo A, Grassi G, Neri F. Laser light triggered smart release of silibinin from a PEGylated-PLGA gold nanocomposite. J Mater Chem B. 2015;3:9023-9032.

22. Mineo PG, Foti C, Vento F, et al. Salinomycin-loaded PLA nanoparticles: drug quantification by GPC and wave voltammetry and biological studies on osteosarcoma cancer stem cells. Anal Bioanal Chem. 2020;412:4681-4690. doi:10.1007/s00216-02002721-6

23. Liénard R, Montesi M, Panseri S, et al. Design of naturally inspired jellyfish-shaped cyclo-polylactides to manage osteosarcoma cancer stem cells fate. Mater Sci Eng C. 2020;117:111291. doi:10.1016/j.msec.2020.111291

24. Lee PW, Pokorski JK. Poly(lactic-co-glycolic acid) devices: production and applications for sustained protein delivery. Wiley Interdiscip Rev Nanomed Nanobiotechnol. 2018;10:e1516. doi:10.1002/wnan.1516

25. Zhao J, Weng G, Li J, Zhu J, Zhao J. Polyester-based nanoparticles for nucleic acid delivery. Mater Sci Eng C. 2018;92:983-994. doi:10.1016/j.msec.2018.07.027

26. Mitchell MJ, Billingsley MM, Haley RM, Wechsler ME, Peppas NA, Langer R. Engineering precision nanoparticles for drug delivery. Nat Rev Drug Discov. 2021;20:101-124.

27. Onoue S, Yamada S, Chan H. Nanodrugs: pharmacokinetics and safety. Int J Nanomedicine. 2014;9:1025-1037. doi:10.2147/IJN. S38378

28. Kemp JA, Shim MS, Heo CY, Kwon YJ. "Combo" nanomedicine: co-delivery of multi-modal therapeutics for efficient, targeted, and safe cancer therapy. Adv Drug Deliv Rev. 2016;98:3-18.

29. Jin M, Jin G, Kang L, Chen L, Gao Z, Huang W. Smart polymeric nanoparticles with $\mathrm{pH}$-responsive and $\mathrm{PEG}$-detachable properties for co-delivering paclitaxel and survivin siRNA to enhance antitumor outcomes. Int $J$ Nanomedicine. 2018;13:2405-2426. doi:10.2147/IJN.S161426

30. Xu C-F, Iqbal S, Shen S, Luo Y-L, Yang X, Wang J. Development of "CLAN" nanomedicine for nucleic acid therapeutics. Small. 2019;15(16):1900055. doi:10.1002/sml1.201900055

31. Ashrafizadeh M, Delfi M, Hashemi F, et al. Biomedical application of chitosan-based nanoscale delivery systems: potential usefulness in siRNA delivery for cancer therapy. Carbohydr Polym. 2021;260:117809.
32. Mirzaei S, Mahabady MK, Zabolian A, et al. Small interfering RNA (siRNA) to target genes and molecular pathways in glioblastoma therapy: current status with an emphasis on delivery systems. Life Sci. 2021;275:119368. doi:10.1016/j.1fs.2021.11 9368

33. Mirzaei S, Gholami MH, Hashemi F, et al. Employing siRNA tool and its delivery platforms in suppressing cisplatin resistance: approaching to a new era of cancer chemotherapy. Life Sci. 2021;277:119430.

34. Dana H, Chalbatani GM, Habibollah M. Molecular mechanisms and biological functions of siRNA. Int $J$ Biomed Sci. 2017;13:48-57.

35. Saw PE, Song EW. siRNA therapeutics: a clinical reality. Sci China Life Sci. 2020;63:485-500. doi:10.1007/s11427-0189438-y

36. Yin H, Kanasty RL, Eltoukhy AA, Vegas AJ, Dorkin JR, Anderson DG. Non-viral vectors for gene-based therapy. Nat Rev Genet. 2014;15:541-555. doi:10.1038/nrg3763

37. Nikam RR, Gore KR. Journey of siRNA: clinical developments and targeted delivery. Nucleic Acid Ther. 2018;28:209-224. doi:10.1089/nat.2017.0715

38. Ginn SL, Amaya AK, Alexander IE, Edelstein M, Abedi MR. Gene therapy clinical trials worldwide to 2017: an update. J Gene Med. 2018;20:1-16. doi:10.1002/jgm.3015

39. Lundstrom K. Are viral vectors any good for RNAi antiviral therapy? Viruses. 2020;12:8-13.

40. Springer AD, Dowdy SF. GalNAc-siRNA conjugates: leading the way for delivery of RNAi therapeutics. Nucleic Acid Ther. 2018;28:109-118. doi:10.1089/nat.2018.0736

41. Ashrafizadeh M, Hushmandi K, Rahmani Moghadam E, et al. Progress in delivery of siRNA-based therapeutics employing nano-vehicles for treatment of prostate cancer. Bioengineering. 2020;7:91. doi:10.3390/bioengineering7030091

42. Ashrafizadeh M, Zarrabi A, Hushmandi K, et al. Progress in natural compounds/siRNA Co-delivery employing nanovehicles for cancer therapy. ACS Comb Sci. 2020;22:669-700. doi:10.1021/acscombsci.0c00099

43. Taxman DJ, Moore CB, Guthrie EH, Huang MTH. Short hairpin RNA (shRNA): design, delivery, and assessment of gene knockdown. In: Sioud M, editor. RNA Therapeutics. Methods in Molecular Biology (Methods and Protocols). Vol. 629. Humana Press; 2010.

44. Acharya R. The recent progresses in shRNA-nanoparticle conjugate as a therapeutic approach. Mater Sci Eng C. 2019;104:109928. doi:10.1016/j.msec.2019.109928

45. Li H, Wang Z, Zhang J, et al. Enhanced shRNA delivery by the combination of polyethylenimine, ultrasound, and nanobubbles in liver cancer. Technol Health Care. 2019;27(S1):263-272. doi:10.3233/THC-199025

46. Wang L, Cho KB, Li Y, Tao G, Xie Z, Guo B. Long noncoding RNA (lncRNA)-mediated competing endogenous RNA networks provide novel potential biomarkers and therapeutic targets for colorectal cancer. Int J Mol Sci. 2019;20:5758. doi:10.3390/ ijms20225758

47. Bhan A, Soleimani M, Mandal SS. Long noncoding RNA and cancer: a new paradigm. Cancer Res. 2017;77:3965-3981. doi:10.1158/0008-5472.CAN-16-2634

48. Adams BD, Parsons C, Walker L, Zhang WC, Slack FJ. Targeting noncoding RNAs in disease. J Clin Invest. 2017;127:761-771. doi:10.1172/JCI84424

49. Matsui M, Corey D. Non-coding RNAs as drug targets. Nat Rev Drug Discov. 2017;16:167-179. doi:10.1038/nrd.2016.117

50. Rao Y, Fang Y, Tan W, et al. Delivery of long non-coding RNA NEAT1 by peripheral blood monouclear cells-derived exosomes promotes the occurrence of rheumatoid arthritis via the MicroRNA-23a/MDM2/SIRT6 axis. Front Cell Dev Biol. 2020;8:952. doi:10.3389/fcell.2020.551681 
51. Koscianska E, Starega-Roslan J, Krzyzosiak WJ. The role of dicer protein partners in the processing of microrna precursors. PLoS One. 2011;6:e28548. doi:10.1371/journal.pone.0028548

52. Bartel DP. MicroRNA target recognition and regulatory functions. Cell. 2009;136:215-233. doi:10.1016/j.cell.2009.01.002

53. Bernardo BC, Ooi JYY, Lin RCY, Mcmullen JR. miRNA therapeutics: a new class of drugs with potential therapeutic applications in the heart. Future Med Chem. 2015;7:1771-1792. doi: $10.4155 / \mathrm{fmc} .15 .107$

54. Lu TX, Rothenberg ME. MicroRNA. J Allergy Clin Immunol. 2018;141:1202-1207. doi:10.1016/j.jaci.2017.08.034

55. O'Brien J, Hayder H, Zayed Y, Peng C. Overview of MicroRNA biogenesis, mechanisms of actions, and circulation. Front Endocrinol. 2018;9:402. doi:10.3389/fendo.2018.00402

56. Ganju A, Khan S, Hafeez BB, et al. miRNA nanotherapeutics for cancer. Drug Discov Today. 2017;22:424-432. doi:10.1016/j. drudis.2016.10.014

57. Wu M, Wang G, Tian W, Deng Y, Xu Y. MiRNA-based therapeutics for lung cancer. Curr Pharm Des. 2018;23:5989-5996. doi:10.2174/1381612823666170714151715

58. Kowalski PS, Rudra A, Miao L, Anderson DG. Delivering the messenger: advances in technologies for therapeutic mRNA delivery. Mol Ther. 2019;27:710-728. doi:10.1016/j.ymthe.2019.02.012

59. Zarghampoor F, Azarpira N, Khatami SR, Behzad-Behbahani A, Foroughmand AM. Improved translation efficiency of therapeutic mRNA. Gene. 2019;707:231-238. doi:10.1016/j.gene.2019.05. 008

60. Zhou L, Qin Z, Zhu Y, He Z, Xu T. Current RNA-based therapeutics in clinical trials. Curr Gene Ther. 2019;19:172-196. doi:10.2174/1566523219666190719100526

61. Guan S, Rosenecker J. Nanotechnologies in delivery of mRNA therapeutics using nonviral vector-based delivery systems. Gene Ther. 2017;24:133-143. doi:10.1038/gt.2017.5

62. Pardi N, Hogan MJ, Weissman D. Recent advances in mRNA vaccine technology. Curr Opin Immunol. 2020;65:14-20. doi:10. 1016/j.coi.2020.01.008

63. Kumar A, Dowling WE, Gómez Román R, et al. Status report on COVID-19 vaccines development. Curr Infect Dis. 2021;23:9. doi:10.1007/s11908-021-00752-3

64. Buck J, Grossen P, Cullis PR, Huwyler J, Witzigmann D. Lipidbased DNA therapeutics: hallmarks of non-viral gene delivery. ACS Nano. 2019;13:3754-3782. doi:10.1021/acsnano.8b07858

65. Anguela XM, High KA. Entering the modern era of gene therapy. Annu Rev Med. 2019;70:273-288. doi:10.1146/annurev-med $-012017-043332$

66. Shi B, Zheng M, Tao W, et al. Challenges in DNA delivery and recent advances in multifunctional polymeric DNA delivery systems. Biomacromol. 2017;18:2231-2246. doi:10.1021/acs. biomac. 7b00803

67. Wahane A, Waghmode A, Kapphahn A, Dhuri K, Gupta A, Bahal R. Role of lipid-based and polymer-based non-viral vectors in nucleic acid delivery for next-generation gene therapy. Molecules. 2020;25:2866. doi:10.3390/molecules25122866

68. Nayerossadat N, Maedeh T, Ali PA. Viral and nonviral delivery systems for gene delivery. Adv Biomed Res. 2012;1:27. doi:10.4103/2277-9175.98152

69. Keeler AM, Flotte TR. Recombinant adeno-associated virus gene therapy in light of luxturna (and zolgensma and glybera): where are we, and how did we get here? Annu Rev Virol. 2019;6:601-621. doi:10.1146/annurev-virology-092818-015530

70. Atasheva S, Shayakhmetov DM. Oncolytic viruses for systemic administration: engineering a whole different animal. Mol Ther. 2021;29:904-907. doi:10.1016/j.ymthe.2021.02.001

71. Howells A, Marelli G, Lemoine NR, Wang Y. Oncolytic virus-interaction of virus and tumor cells in the battle to eliminate cancer. Front Oncol. 2017;7:195. doi:10.3389/fonc.2017.00195
72. Donnelley M, Parsons DW. Gene therapy for cystic fibrosis lung disease: overcoming the barriers to translation to the clinic. Front Pharmacol. 2018;9:1381. doi:10.3389/fphar.2018.01381

73. Brescia M, Janssen JM, Liu J, Goncalves MAFV. High-capacity adenoviral vectors permit robust and versatile testing of DMD gene repair tools and strategies in human cells. Cells. 2020;9:869. doi:10.3390/cells9040869

74. Li Z, Ho W, Bai X, Li F, Chen Y-J, Zhang X-Q XX. Nanoparticle depots for controlled and sustained gene delivery. J Contr Rel. 2020;322:622-631. doi:10.1016/j.jconrel.2020.03.021

75. Huang D, Cao Y, Yang X, et al. A nanoformulation-mediated multifunctional stem cell therapy with improved beta-amyloid clearance and neural regeneration for alzheimer's disease. $A d v$ Mater. 2021;33:2006357. doi:10.1002/adma.202006357

76. Proulx J, Joshi C, Vijayaraghavalu S, et al. Arginine-modified polymers facilitate poly (lactide-co-glycolide)-based nanoparticle gene delivery to primary human astrocytes. Int $J$ Nanomed. 2020;15:3639-3647. doi:10.2147/IJN.S250865

77. Liu C, Xie Y, Li X, et al. Folic acid/peptides modified PLGA-PEI-PEG polymeric vectors as efficient gene delivery vehicles: synthesis, characterization and their biological performance. Mol Biotechnol. 2021;63:63-79. doi:10.1007/ s12033-020-00285-5

78. Sukumar UK, Rajendran JCB, Gambhir SS, Massoud TF, Paulmurugan R. SP94-targeted triblock copolymer nanoparticle delivers thymidine kinase-p53-nitroreductase triple therapeutic gene and restores anticancer function against hepatocellular carcinoma in vivo. ACS Appl Mater Interfaces. 2020;12:113 07-11319. doi:10.1021/acsami.9b20071

79. Devulapally R, Lee T, Barghava-Shah A, et al. Ultrasound-guided delivery of thymidine kinase-nitroreductase dual therapeutic genes by PEGylated-PLGA/PIE nanoparticles for enhanced triple negative breast cancer therapy. Nanomedicine. 2018;13:10 51-1066. doi:10.2217/nnm-2017-0328

80. Hazekawa $M$, Nishinakagawa $T$, Kawakubo-Yasukochi $T$, Nakashima M. Glypican-3 gene silencing for ovarian cancer using siRNA-PLGA hybrid micelles in a murine peritoneal dissemination model. J Pharmacol Sci (Amsterdam, Netherlands). 2019;139:231-239.

81. Chen Z, Liang Y, Feng X, et al. Vitamin-B12-conjugated PLGA-PEG nanoparticles incorporating miR-532-3p induce mitochondrial damage by targeting apoptosis repressor with caspase recruitment domain (ARC) on CD320-overexpressed gastric cancer. Mater Sci Eng C. 2021;120:111722. doi:10.1016/j. msec.2020.111722

82. Lin WJ, Lee WC. Polysaccharide-modified nanoparticles with intelligent CD44 receptor targeting ability for gene delivery. Int J Nanomed. 2018;13:3989-4002. doi:10.2147/IJN.S163 149

83. Yu M, Wang K, Han Z, et al. DOTAP-incorporated PEG-PLGA nanoparticles for efficient in vitro and in vivo gene delivery. J Biomed Nanotechnol. 2018;14:281-293. doi:10.1166/jbn.20 18.2470

84. Zhao G, Liu A, Zhang Y, et al. Nanoparticle-delivered siRNA targeting Bruton's tyrosine kinase for rheumatoid arthritis therapy. Biomater Sci. 2019;7:4698-4707. doi:10.1039/C9BM010 $25 \mathrm{D}$

85. Luo YL, Xu CF, Li HJ, et al. Macrophage-specific in vivo gene editing using cationic lipid-assisted polymeric nanoparticles. ACS Nano. 2018;12:994-1005. doi:10.1021/acsnano.7b07874

86. Fan YN, Li M, Luo YL, et al. Cationic lipid-assisted nanoparticles for delivery of mRNA cancer vaccine. Biomater Sci. 2018;6:3009-3018. doi:10.1039/C8BM00908B

87. Miao L, Zhang Y, Huang L. mRNA vaccine for cancer immunotherapy. Mol Cancer. 2021;20:41. doi:10.1186/s12943021-01335-5 
88. Chen Q, Gao M, Li Z, et al. Biodegradable nanoparticles decorated with different carbohydrates for efficient macrophage-targeted gene therapy. J Contr Rel. 2020;323:179-190. doi:10.1016/j.jconrel. 2020.03.044

89. Katebi A, Varshochian R, Riazirad F, Ganjalikhani-Hakemi M, Ajdary S. Combinatorial delivery of antigen and TLR agonists via PLGA nanoparticles modulates Leishmania major infected-macrophages activation. Biomed Pharmacother. 2021;137:111276. doi:10.1016/j.biopha.2021.111276

90. Hao X, Li Q, Wang H, et al. Red-blood-cell-mimetic gene delivery systems for long circulation and high transfection efficiency in ECs. J Mater Chem B Mater Biol Med. 2018;6:5975-5985. doi:10.1039/C8TB01789A

91. Zhou YL, Yang QQ, Yan YY, et al. Gene-loaded nanoparticle-coated sutures provide effective gene delivery to enhance tendon healing. Mol Ther. 2019;27:1534-1546. doi:10.1016/j.ymthe.2019.05.024

92. Yang QQ, Shao YX, Zhang LZ, Zhou YL. Therapeutic strategies for flexor tendon healing by nanoparticle-mediated co-delivery of bFGF and VEGFA genes. Colloids Surf B. 2018;164:165-176. doi:10.1016/j.colsurfb.2018.01.031

93. Shi R, Lian W, Han S, et al. Nanosphere-mediated co-delivery of VEGF-A and PDGF-B genes for accelerating diabetic foot ulcers healing in rats. Gene Ther. 2018;25:425-438. doi:10.1038/ s41434-018-0027-6

94. Amani A, Alizadeh MR, Yaghoubi H, Ebrahimi H. Design and fabrication of novel multi-targeted magnetic nanoparticles for gene delivery to breast cancer cells. J Drug Deliv Sci Technol. 2021;61:102151. doi:10.1016/j.jddst.2020.102151

95. Liu X, Wang B, Li Y, et al. Powerful anticolon tumor effect of targeted gene immunotherapy using folate-modified nanoparticle delivery of CCL19 to activate the immune system. ACS Cent Sci. 2019;5:277-289. doi:10.1021/acscentsci.8b00688

96. Liu X, Li Y, Sun X, et al. Powerful anti-colon cancer effect of modified nanoparticle-mediated IL-15 immunogene therapy through activation of the host immune system. Theranostics. 2018;8:3490-3503. doi:10.7150/thno.24157

97. Liu X, Gao X, Zheng S, et al. Modified nanoparticle mediated IL-12 immunogene therapy for colon cancer. Nanomedicine (New York, NY, United States). 2017;13:1993-2004.

98. Wu T, Cai Y, Zhao X, et al. Synthesis and characterization of poly (ethylene oxide)/polylactide/polylysine tri-arm star copolymers for gene delivery. $J$ Polym Sci a Polym Chem. 2018;56:635-644. doi:10.1002/pola.28938

99. Xu C, Li D, Cao Z, Xiong M, Yang X, Wang J. Facile hydrophobization of siRNA with anticancer drug for non-cationic nanocarrier-mediated systemic delivery. Nano Lett. 2019;19:2688-2693. doi:10.1021/acs.nanolett.9b00657

100. $\mathrm{Xu} \mathrm{X,} \mathrm{Wan} \mathrm{T,} \mathrm{Xin} \mathrm{H,} \mathrm{et} \mathrm{al.} \mathrm{Delivery} \mathrm{of} \mathrm{CRISPR/Cas9} \mathrm{for}$ therapeutic genome editing. J Gene Med. 2019;21:e3107. doi:10.1002/jgm.3107

101. Wan T, Niu D, Wu C, Xu FJ, Church G, Ping Y. Material solutions for delivery of CRISPR/Cas-based genome editing tools: current status and future outlook. Mater Today. 2019;26:40-66. doi:10.1016/j.mattod.2018.12.003

102. Hendel A, Bak RO, Clark JT, et al. Chemically modified guide RNAs enhance CRISPR-Cas genome editing in human primary cells. Nat Biotechnol. 2015;33:985-989. doi:10.1038/ nbt. 3290

103. $\mathrm{Xu} \mathrm{CF}$, Chen GJ, Luo YL, et al. Rational designs of in vivo CRISPR-Cas delivery systems. Adv Drug Del Rev. 2021;168:3-29. doi:10.1016/j.addr.2019.11.005

104. Xu C, Lu Z, Luo Y, et al. Targeting of NLRP3 inflammasome with gene editing for the amelioration of inflammatory diseases. Nat Commun. 2018;9:4092. doi:10.1038/s41467-01806522-5
105. Zhang $\mathrm{Y}$, Shen $\mathrm{S}$, Zhao $\mathrm{G}$, et al. In situ repurposing of dendritic cells with CRISPR/Cas9-based nanomedicine to induce transplant tolerance. Biomaterials. 2019;217:119302. doi:10.1016/j. biomaterials.2019.119302

106. Luo YL, Liang LF, Gan YJ, et al. An all-in-one nanomedicine consisting of CRISPR-Cas9 and an autoantigen peptide for restoring specific immune tolerance. ACS Appl Mater Interfaces. 2020;12:48259-48271. doi:10.1021/acsami.0c10885

107. Zhang S, Shen J, Li D, Cheng Y. Strategies in the delivery of Cas9 ribonucleoprotein for CRISPR/Cas9 genome editing. Theranostics. 2021;11:614-648. doi:10.7150/thno.47007

108. Cordaro A, Neri G, Sciortino MT, Scala A, Piperno A. Graphenebased strategies in liquid biopsy and in viral diseases diagnosis. Nanomaterials. 2020;10:1014. doi:10.3390/nano10061014

109. Guglielmi G. First CRISPR test for the coronavirus approved in the United States. Nature News; 2020. Available from: www. nature.com/articles/d41586-020-01402-9. Accessed August 12, 2021.

110. Abbott TR, Dhamdhere G, Liu Y, et al. Development of CRISPR as an antiviral strategy to combat SARS-CoV-2 and influenza. Cell. 2020;181:865-876. doi:10.1016/j.cell.2020.04.020

111. Lotfi M, Rezaei N. CRISPR/Cas13: a potential therapeutic option of COVID-19. Biomed Pharmacother. 2020;131:110738. doi:10.1016/j.biopha.2020.110738

112. Poduri R, Joshi G, Jagadeesh G. Drugs targeting various stages of the SARS-CoV-2 life cycle: exploring promising drugs for the treatment of Covid-19. Cell Signal. 2020;74:109721. doi:10.1016/ j.cellsig.2020.109721

113. Citarella A, Scala A, Piperno A, Micale N. SARS-CoV-2 Mpro: a potential target for peptidomimetics and small-molecule inhibitors. Biomolecules. 2021;11:607. doi:10.3390/biom11040607

114. Mansourabadi AH, Sadeghalvad M, Mohammadi-Motlagh HR, Rezaei N. The immune system as a target for therapy of SARS-CoV-2: a systematic review of the current immunotherapies for COVID-19. Life Sci. 2020;258:118185. doi:10.1016/j. lfs. 2020.118185

115. Malik JA, Mulla AH, Farooqi T, Pottoo FH, Anwar S, Rengasamy KRR. Targets and strategies for vaccine development against SARS-CoV-2. Biomed Pharmacother. 2021;137:111254. doi:10.1016/j.biopha.2021.111254

116. Machhi J, Shahjin F, Das S, et al. Nanocarrier vaccines for SARS-CoV-2. Adv Drug Del Rev. 2021;171:215-239.

117. Mulligan MJ, Lyke KE, Kitchin N, et al. Phase I/II study of COVID-19 RNA vaccine BNT162b1 in adults. Nature. 2020;586:589-593. doi:10.1038/s41586-020-2639-4

118. Jackson LA, Anderson EJ, Nadine G. Rouphael, An mRNA vaccine against SARS-CoV-2 - preliminary report. $N$ Engl $J$ Med. 2020;383:1920-1931. doi:10.1056/NEJMoa2022483

119. World Health Organization. Background document on the mRNA vaccine BNT162b2 (Pfizer-BioNTech) against COVID-19, 2021. Available from: https://www.who.int/publications/i/item/back ground-document-on-mrna-vaccine-bnt162b2-(pfizer-biontech)against-covid-19. Accessed August 12, 2021.

120. Belete TM. Review on up-to-date status of candidate vaccines for COVID-19 disease. Infect Drug Resist. 2021;14:151-161. doi:10.2147/IDR.S288877

121. Kim J, Eygeris Y, Gupta M, Sahay G. Self-assembled mRNA vaccines. Adv Drug Deliv Rev. 2021;170:83-112.

122. Schoenmaker L, Witzigmann D, Kulkarni JA, et al. mRNAlipid nanoparticle COVID-19 vaccines: structure and stability. Int J Pharm. 2021;601:120586. doi:10.1016/j.ijpharm.2021. 120586

123. Chung JY, Thone MN, Kwon YJ. COVID-19 vaccines: the status and perspectives in delivery points of view. Adv Drug Deliv Rev. 2021;170:1-25. 
124. Lim M, Badruddoza AZM, Firdous J, et al. Engineered nanodelivery systems to improve DNA vaccine technologies. Pharmaceutics. 2020;12:30. doi:10.3390/pharmaceutics 12010 030

125. Malyala P, O'Hagan DT. Chapter 12 - polymeric particles as vaccine delivery systems. In: Virgil EJC, Schijns DT, O’Hagan, editors. Immunopotentiators in Modern Vaccines. 2nd ed. Academic Press; 2017:231-248.

126. Chauhan G, Madou MJ, Kalra S, Chopra V, Ghosh D, MartinezChapa SO. Nanotechnology for COVID-19: therapeutics and vaccine research. ACS Nano. 2020;14:7760-7782. doi:10.1021/ acsnano.0c04006

127. Lin LC-W, Huang CY, Yao B-Y, et al. Viromimetic STING agonist-loaded hollow polymeric nanoparticles for safe and effective vaccination against middle east respiratory syndrome coronavirus. Adv Funct Mater. 2019;29:1807616. doi:10.1002/ adfm.201807616
128. Medhi R, Srinoi P, Ngo N, Tran H-V, Lee TR. Nanoparticle-based strategies to combat COVID-19. ACS Appl Nano Mater. 2020;3:8557-8580. doi:10.1021/acsanm.0c01978

129. Vaccines Guidance Document. Status of COVID-19 Vaccines within WHO EUL/PQ evaluation process. Available from: https:/extranet.who.int/pqweb/sites/default/files/documents/ Status_COVID_VAX_16Feb2021.pdf. Accessed April 30, 2021.

130. Burger L. Healthcare \& Pharmaceuticals. CureVac fails in pivotal COVID-19 vaccine trial with $47 \%$ efficacy. Available from: https://www.reuters.com/business/healthcare-pharmaceuticals/cur evacs-covid-19-vaccine-misses-efficacy-goal-mass-trial-2021-0616. Accessed August 12, 2021.

131. CureVac Provides Update on Phase $2 b / 3$ Trial of First-Generation COVID-19 Vaccine Candidate, $\mathrm{CVnCoV}$ (press release). Available from: https://www.curevac.com/en/2021/06/16/curevacprovides-update-on-phase-2b-3-trial-of-first-generation-covid-19vaccine-candidate-cvncov/. Accessed August 12, 2021.

\section{Publish your work in this journal}

The International Journal of Nanomedicine is an international, peerreviewed journal focusing on the application of nanotechnology in diagnostics, therapeutics, and drug delivery systems throughout the biomedical field. This journal is indexed on PubMed Central, MedLine, CAS, SciSearch ${ }^{\mathbb{R}}$, Current Contents ${ }^{\mathbb{R}} /$ Clinical Medicine, $^{-}$
Journal Citation Reports/Science Edition, EMBase, Scopus and the Elsevier Bibliographic databases. The manuscript management system is completely online and includes a very quick and fair peer-review system, which is all easy to use. Visit http://www.dovepress.com/ testimonials.php to read real quotes from published authors. 